\title{
Fabrication and Physico-Chemical Properties of Antifungal Samarium Doped Hydroxyapatite Thin Films
}

\author{
Carmen Steluta Ciobanu ${ }^{1}$, Daniela Predoi ${ }^{1, *}$, Patrick Chapon ${ }^{2}$, Mihai Valentin Predoi ${ }^{3}$ \\ and Simona Liliana Iconaru $1, *$ (D) \\ 1 National Institute of Materials Physics, Atomistilor Street, No. 405A, P.O. Box MG 07, 077125 Magurele, \\ Romania; ciobanucs@gmail.com \\ 2 HORIBA FRANCE S.A.S., Boulevard Thomas Gobert, Passage Jobin Yvon, 91120 Palaiseau, France; \\ patrick.chapon@horiba.com \\ 3 Department of Mechanics, University Politehnica of Bucharest, BN 002, 313 Splaiul Independentei, Sector 6, \\ 060042 Bucharest, Romania; predoi@gmail.com \\ * Correspondence: dpredoi@gmail.com (D.P.); simonaiconaru@gmail.com (S.L.I.)
}

check for updates

Citation: Ciobanu, C.S.; Predoi, D.; Chapon, P.; Predoi, M.V.; Iconaru, S.L Fabrication and Physico-Chemical Properties of Antifungal Samarium Doped Hydroxyapatite Thin Films. Coatings 2021, 11, 1466. https:// doi.org/10.3390/coatings11121466

Academic Editor: Enrico Sassoni

Received: 30 October 2021

Accepted: 27 November 2021

Published: 29 November 2021

Publisher's Note: MDPI stays neutral with regard to jurisdictional claims in published maps and institutional affiliations.

Copyright: (C) 2021 by the authors. Licensee MDPI, Basel, Switzerland. This article is an open access article distributed under the terms and conditions of the Creative Commons Attribution (CC BY) license (https:/ / creativecommons.org/licenses/by/ $4.0 /)$.

\begin{abstract}
Samarium doped hydroxyapatite $\left(\mathrm{Ca}_{10-\mathrm{x}} \mathrm{Sm}_{\mathrm{x}}\left(\mathrm{PO}_{4}\right)_{6}(\mathrm{OH})_{2}, \mathrm{x}_{\mathrm{Sm}}=0.5,50 \mathrm{SmHAp}\right)$ is a very promising candidate to be used for different coatings in various dental and orthopedic implants. We report, for the first time, the obtaining of 50SmHAp thin films by a cost-effective method, namely spin coating. Thin films of 50SmHAp on silicon substrate have been analyzed by various techniques such as Fourier transform infrared spectroscopy (FTIR), scanning electron microscopy (SEM), atomic force microscopy (AFM), Metallographic microscopy and Glow Discharge Optical Emission Spectroscopy (GDOES). The stability of 50SmHAp suspension was evaluated by ultrasound measurements. Fourier transform infrared spectroscopy (FTIR), transmission electron microscopy (TEM) and scanning electron microscopy (SEM) were also used to evaluate the 50SmHAp suspension. The antifungal activity of 50SmHAp suspension and coatings was assessed using Candida albicans ATCC 10231 fungal strain (C. albicans). The results of the antifungal assays depicted that both 50SmHAp suspensions and coatings were effective in inhibiting the development of $C$. albicans fungal cells, thus making them ideal candidates for the development of novel antifungal agents. The obtained results give new perspective for possible applications of 50SmHAp thin films in various medical applications due to their antifungal properties.
\end{abstract}

Keywords: samarium; hydroxyapatite; spin-coating; coatings; morphology; antifungal assay

\section{Introduction}

Currently, the use of biocomposites in areas such as implantology and dentistry is growing. One of the most studied biomaterial with possible biomedical applications is hydroxyapatite (HAp). Due to its unique biological properties (biocompatibility, bioactivity, osteoconductivity, etc.), HAp could be used successfully in orthopaedics and dentistry [1,2]. In general, hydroxyapatite is a stoichiometric calcium phosphate, stable with a Ca/P molar ratio equal to 1.67 [2]. On the other hand, the structure of HAp allows a various number of ionic substitutions of $\mathrm{Ca}^{2+}$ ions from their structure. The presence of foreign ions $\left(\mathrm{Ag}^{+}\right.$, $\mathrm{Eu}^{3+}, \mathrm{Sm}^{3+}, \mathrm{Zn}^{2+}$, etc.) in its structure improve both the physicochemical and the biological properties, thus increasing the area of applicability of this special biomaterial [2-7].

It is well known, that Samarium $\left(\mathrm{Sm}^{3+}\right)$ is a lanthanide that could enhance both antimicrobial [8] and photoluminescent properties [9] of the host materials. Recent studies, have also shown that the biological activity of samarium doped hydroxyapatite (SmHAp) it is strongly influenced by the amount of $\mathrm{Sm}^{3+}$ that is found in the samples [10-14]. Moreover, has been highlighted that the presence of $\mathrm{Sm}^{3+}$ in various biomaterials, used in the medical field, increases their anticancer activity $[15,16]$. Ying L. and collaborators, in their study 
entitled "Long-term biodistribution in vivo and toxicity of radioactive/magnetic hydroxyapatite nanorods", showed that Sm-HA:Gd nanorods exhibit an excellent $\gamma$-emission, relaxivity and biocompatibility thus making them suitable for potential applications in the biomedical area (including single-photon emission computed tomography (SPECT) and magnetic resonance imaging (MRI) [17]. Moreover, according to previous studies, the presence of lanthanide ions on surface of the magnesium alloys induces a superior corrosion resistance, anticancer and antimicrobial activity [16]. The interaction between the implant surface and the surrounding tissue is essential and thus it becomes imperative to obtain coatings with improved biological and antimicrobial properties and finally high-performance implants [18]. Furthermore, previous studies showed that samarium-based compounds, obtained by various techniques could be used in fields such as: nuclear nanomedicine $[19,20]$, molecular dual-targeted radiotherapy of hepatocellular carcinoma [21], low-temperature solid oxide fuel cell application [22], white light-emitting diodes [23], biosensing applications in biological fluids [24], high-density optical memory devices [25], etc. It is well known, that hydroxyapatite coatings could be obtained by various techniques including: pulsed laser deposition (PLD) [26]; thermal evaporation technique [10], rf magnetron sputtering [12,18], dip coating [18,27], spin coating [18], electrochemical and hydrothermal synthesis [28], etc. One of the widely used deposition technique is spin coating, due to the fact that it is a simple route that allows the obtaining of uniform and homogeneous layers at low temperatures $[29,30]$.

One of the major complications that could appear after implant related surgery and lead to the rejection of the implant is the occurrence of infection with Candida albicans fungal strain [31,32]. Therefore, in order to combat this major health problem, it is important to use implants coated with biomaterials with intrinsic antimicrobial properties $[31,32]$ such as samarium-doped hydroxyapatite [13].

The results of our previous studies conducted on samarium doped hydroxyapatite $\left(\mathrm{x}_{\mathrm{Sm}}=0.05\right.$ and 0.1$)$ coatings deposited on Si substrate showed, on the one hand their improved biocompatibility with the gingival, HeLa and osteoblastic cells line and on the other hand a superior antimicrobial activity (against Staphylococcus aureus, Enterococcus faecalis, Escherichia coli, Pseudomonas aeruginosa and Candida albicans microbial strain) [11-14]. Therefore, due to these new improved biological properties, this type of materials could be used in many medical applications.

As far as we know, no previous studies have been performed on samarium doped hydroxyapatite $\left(\mathrm{x}_{\mathrm{Sm}}=0.5,50 \mathrm{SmHAp}\right)$ coatings deposited on Si substrate through spin coating method for biomedical application (such as prosthesis coating, implantology, stomatology, etc.). Therefore, it is valuable to investigate the physicochemical and antimicrobial properties of 50SmHAp suspension and coatings to see the extent to which they can be used in such bioapplications. The purpose of this research was to prove that an adapted co-precipitation method is adequate to obtained a stabile suspension for the fabrication of samarium doped hydroxyapatite $\left(\mathrm{Ca}_{10-x} \mathrm{Sm}_{x}\left(\mathrm{PO}_{4}\right)_{6}(\mathrm{OH})_{2}, \mathrm{x}_{\mathrm{Sm}}=0.5,50 \mathrm{SmHAp}\right)$ thin films on Si substrate by spin-coating technique. The aim of this work was to synthesize the stabile suspension of 50SmHAp ( $\left.x_{S m}=0.5\right)$ in order to produce uniform coatings. We have demonstrated that a simple procedure such as spin-coating technique allows the obtaining of thin films of SmHAp with antifungal properties. To the best of our knowledge, this is the first time that spin-coating technique has been used to realize thin films of SmHAp $\left(x_{S m}=0.5\right)$.

The 50SmHAp suspensions were investigated from the point of view of stability by ultrasonic measurements and from morphological point of view by transmission electron microscopy (TEM) and scanning electron microscopy (SEM). The 50SmHAp thin films were characterized using scanning electron microscopy (SEM), atomic force microscopy (AFM), metallographic microscopy (MM), Fourier transform infrared spectroscopy (FTIR), and Glow Discharge Optical Emission Spectroscopy (GDOES). Moreover, the results of the antimicrobial assay performed on 50SmHAp suspension and coatings against Candida albicans ATCC 10231 (C. albicans) fungal strain are presented, respectively. 


\section{Materials and Methods}

\subsection{Materials}

The samarium doped hydroxyapatite $\left(\mathrm{Ca}_{10-\mathrm{x}} \mathrm{Sm}_{\mathrm{x}}\left(\mathrm{PO}_{4}\right)_{6}(\mathrm{OH})_{2}, \mathrm{x}_{\mathrm{Sm}}=0.5,50 \mathrm{SmHAp}\right)$ suspensions were synthesized using calcium nitrate tetrahydrate, $\mathrm{Ca}\left(\mathrm{NO}_{3}\right)_{2} \cdot 4 \mathrm{H}_{2} \mathrm{O}$ (Sigma Aldrich, St. Louis, MO, USA, $\geq 99.0 \%$ ), ammonium hydrogen phosphate, $\left(\mathrm{NH}_{4}\right)_{2} \mathrm{HPO}_{4}$ (Sigma Aldrich, St. Louis, MO, USA, $\geq 99.0 \%$ ), samarium nitrate hexahydrate, $\mathrm{Sm}\left(\mathrm{NO}_{3}\right)_{3} \cdot 6 \mathrm{H}_{2} \mathrm{O}$ (Alpha Aesar, Landau, Germany, 99.97\% purity), ammonium hydroxide, $\mathrm{NH}_{4} \mathrm{OH}$ [Sigma Aldrich, St. Louis, MO, USA, 25\% $\mathrm{NH}_{3}$ in $\mathrm{H}_{2} \mathrm{O}(\mathrm{T})$ ], deionized water (Milli-DI ${ }^{\circledR}$ Water Purification System for Deionized Water, Merck, Darmstadt, Germany). The ethanol absolute and double-distilled water were also used to achieve 50SmHAp.

\subsection{Samarium Doped Hydroxyapatite Thin Films Using Spin-Coating Technique}

The 50SmHAp samarium doped hydroxyapatite suspensions were synthesized according with previous studies [8,33-35] where $(\mathrm{Ca}+\mathrm{Sm}) / \mathrm{P}$ molar ratio was 1.67 , to obtain a compound that retains the structure of pure hydroxyapatite. The resultant 50SmHAp suspension was aged at $40^{\circ} \mathrm{C}$ for $24 \mathrm{~h}$ before being used for the manufacture of thin films by spin-coating method. In this study the $\mathrm{Si}$ was used as substrate $(7 \mathrm{~mm} \times 7 \mathrm{~mm})$. The degreasing of the substrate was performed with acetone in ultrasonic bath for $10 \mathrm{~min}$. After that, the Si substrate was washed with deionized water and dried at $500{ }^{\circ} \mathrm{C}$ for $30 \mathrm{~min}$ in order to eliminate the remaining contaminants from the substrate surface. The deposited thin films were produced by spin-coating $0.2 \mathrm{~mL}$ of $50 \mathrm{SmHAp}$ suspension at $3500 \mathrm{rpm}$ for $10 \mathrm{~s}$. The 50SmHAp deposited thin films were dried for $15 \mathrm{~min}$ in air at room temperature. The above deposition procedure was repeated in triplicate to obtained films to finally have sufficiently thick films. The final 50SmHAp thin films were thermally treated in an oven at $100{ }^{\circ} \mathrm{C}$ and calcined at $500{ }^{\circ} \mathrm{C}$ for $2 \mathrm{~h}$ (heating rate of $2^{\circ} \mathrm{C} / \mathrm{min}$ ). The synthesis method of Samarium doped hydroxyapatite thin films is revealed in Figure 1.

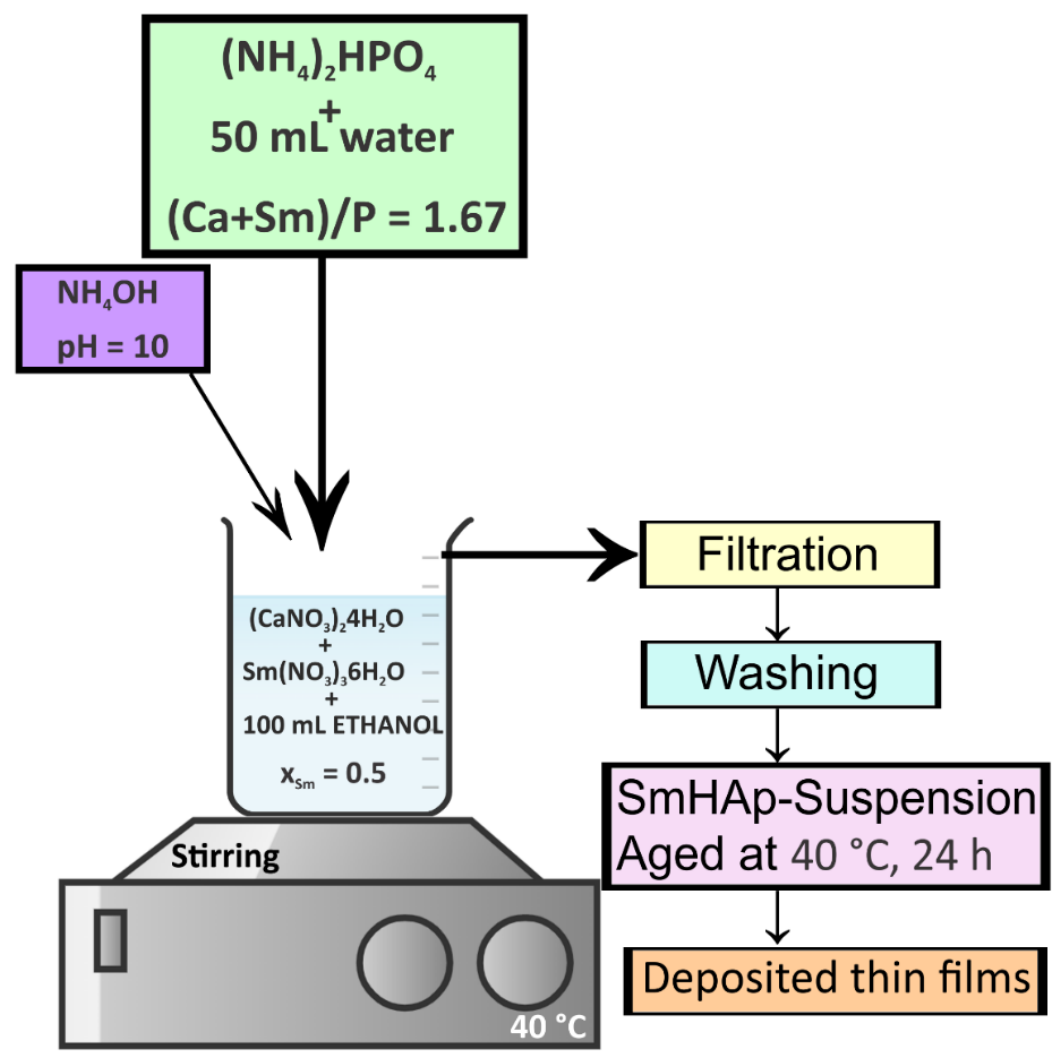

Figure 1. Synthesis method of Samarium doped hydroxyapatite thin films. 


\subsection{Characterization Methods}

The non-destructive ultrasound studies were used in order to evaluated the stability of the suspension used to achieve 50SmHAp thin films [36-38]. As a reference to evaluate the stability of the suspension was used the double-distilled water. Spectral amplitude as a function of frequency for the suspension in relation to reference fluid, relative spectral amplitudes as a function of frequency were used to analyze the stability of the suspension. Attenuation vs. frequency for echo 1 of the suspension and reference fluid and relative spectral amplitudes as a function of time were also used in order to evaluate the stability of the suspension.

The transmission electron microscopy images (bright field mode) were obtained with the aid of a CM 20 instrument (Philips FEI, Eindhoven, The Netherlands) equipped with a Lab6 instrument (which works at $200 \mathrm{kV}$ ). In order to estimate the average particle size $\left(\mathrm{D}_{\text {TEM }}\right), 600$ particles were measured. Additional information regarding the morphology and elemental composition of the studied samples were obtained by scanning electron microscopy (SEM). For this purpose, a Hitachi S4500 instrument (Hitachi, Tokyo, Japan) equipped with an energy-dispersive X-ray (EDX) analyzer (Ametek EDAX Inc., Mahwah, NJ, USA). Prior to being placed on the microscope for analysis, a drop of 50SmHAp suspension was put on a double-sided adhesive carbon tape and dried in vacuum condition. In order to calculate the average particle size $\left(D_{\text {SEM }}\right), 600$ particles were measured. Furthermore, the thin films thickness was also assessed by SEM using a cross sectional image of the coatings. The thickness of the composite layers was estimated from 10 individual measurements on the same image and presented as mean \pm SD. NT-MDT NTEGRA Probe Nano Laboratory instrument (NT-MDT, Moscow, Russia) was used to study the 50SmHAp coatings surface topography. A silicon NT-MDT NSG01 cantilever coated with a $35 \mathrm{~nm}$ gold layer was used for obtaining of the atomic force microscopy (AFM) images in non-contact mode (on a surface area of $10 \mu \mathrm{m} \times 10 \mu \mathrm{m}$ ). Also, the root mean square roughness $\left(\mathrm{R}_{\mathrm{RMS}}\right)$ was estimated. The AFM investigations were carried out in environmental conditions and the data processing was done using Gwyddion 2.55 software (Department of Nanometrology, Czech Metrology Institute, Brno, Czech Republic) [39]. The 3D surface representation of AFM images was obtained using Image J software (ImageJ 1.51j8, National Institutes of Health, Bethesda, MD, USA) [40].

An inversed trinocular metallographic microscope OX.2153-PLM (Euromex, Arnhem, The Netherlands) was used in order to obtain complementary information about the surface morphology of 50SmHAp coatings. The metallographic images were recorded using the $10 \times$ objective of the microscope $(100 \times$ total magnification). The 3D surface representation of the metallographic images was obtained using Image J software (ImageJ 1.51j8, National Institutes of Health, Bethesda, MD, USA) [40].

Fourier transform infrared-Attenuated total reflection (FTIR-ATR) spectra were recorded using a Perkin Elmer SP-100 spectrometer (Waltham, MA, USA) with a resolution of $4 \mathrm{~cm}^{-1}$ in the $400-4000 \mathrm{~cm}^{-1}$ spectral range. The curve fitting analysis and second derivative spectra were obtained using the protocol described in our previous papers [11,41,42].

Depth profiles of the 50SmHAp thin films deposited on the Si substrates by spin coating method were achieved using glow-discharge optical emission spectroscopy (GDOES). The GDOES spectra were obtained using a GD-Profiler 2 (Horiba France SAS Longjumeau, France) instrument operated at working parameters: $650 \mathrm{~Pa}$ (argon atmosphere) with application of RF of $1 \mathrm{kHz}$ and power of $35 \mathrm{~W}$. A circular area with a diameter of about $4 \mathrm{~mm}$ was chosen to detect the signals.

\subsection{In Vitro Antifungal Assays}

The in vitro antifungal studies were performed using the reference fungal strain Candida albicans ATCC 10231 (ATCC, Manassas, VA, USA). The experiments were done with fungal suspensions having an approximate concentration of approximately $10^{5}-10^{6}$ colony forming units (CFU) / $\mathrm{mL}$ as previously reported in [43]. 
The qualitative assay was achieved for three different incubation periods $(24,48$ and $72 \mathrm{~h}$ ) by visualization of $C$. albicans fungal cells on the surface of 50SmHAp coatings by scanning electron microscopy (SEM) and confocal laser scanning microscopy (CLSM). The preparation of the samples for SEM and CLSM studies was realized as previously described in $[44,45]$. The 3D representation of the SEM and CLSM images were obtained with the aid of Image J software (Image J 1.51j8) [40].

The quantitative assays of the antifungal activity of both 50SmHAp suspensions and coatings were performed using an adapted method (E2149-10; ASTM International, West Conshohocken, PA, USA) [46,47], previously described [48]. A well containing only microbial suspension was used as the positive control $(\mathrm{C}+)$. The experiments were performed in triplicate and repeated three times and the results were presented as mean \pm SD.

\section{Results}

The stability of the suspension used to obtain 50SmHAp thin films was evaluated using ultrasound measurements. Several specific parameters were determined for three echoes and here is presented the signal analysis for the first echo. Transmitted ultrasonic signals were recorded during $2500 \mathrm{~s}$, analyzed and compared to double-distilled water, considered as reference fluid, with perfect stability, in the same experimental conditions. The frequency analysis of the recorded signals provided the spectral amplitude as a function of frequency for the suspension of 50SmHAp in relation to reference fluid as shown in Figure 2a. The reference fluid spectrum shows the amplitudes distribution with the frequency that is specific to the transducer used. The maximum observed at around $4 \mathrm{MHz}$ is located at the resonant frequency of the transducer. The stability of the 50SmHAp suspension is proven by the perfect superposition of all spectral amplitudes of the recorded signals. The spectral amplitudes are lower than those in the reference fluid, due to the attenuation. In order to see the dependence of the frequency amplitude without the influence of the transducer characteristic spectrum, the amplitude ratio is determined at each frequency in relation to the reference fluid. The ratios of the spectral amplitudes of the 50SmHAp suspension and the amplitude in the reference fluid are presented in Figure $2 b$. The close to linear decrease of these ratios indicate a linear increasing attenuation with frequency, without sudden variations attributable to elastic resonances of the nanoparticles. Indeed, in Figure $3 a$ is presented this attenuation in nepper/m showing a similar increase with increasing frequency as that of the reference fluid, which is perfectly homogeneous. This linear evolution of the relative amplitudes vs. frequency is typical for dispersions of nanoparticles at relative low frequencies (4 MHz), in accordance with existing references [49]. The amplitudes of signals of the three recorded echoes, relative to the corresponding echoes of the reference fluid (Figure $3 b$ ) highlight the stability over time of the 50SmHAp suspension, by the constancy of these relative amplitudes along the recording time of $2500 \mathrm{~s}$. The stability parameter calculated for the 50SmHAp suspension was $5.47742 \times 10^{-6}(1 / \mathrm{s}$.) This behavior proves the perfect stability of the 50SmHAp suspensions.

Transmission electron microscopy (TEM) was used to investigate the morphology of 50SmHAp suspensions. The results of TEM studies are shown in Figure $4 \mathrm{a}, \mathrm{b}$. Thus, in the TEM micrographs (Figure 4a) obtained on the analyzed sample it can be seen that the nanoparticles have an elongated morphology. Also, the average particle size (obtained from TEM measurements) was estimated (Figure $4 \mathrm{~b}$ ). Therefore, for the 50SmHAp suspension, an average particle size of $8 \pm 2 \mathrm{~nm}$ was obtained. 

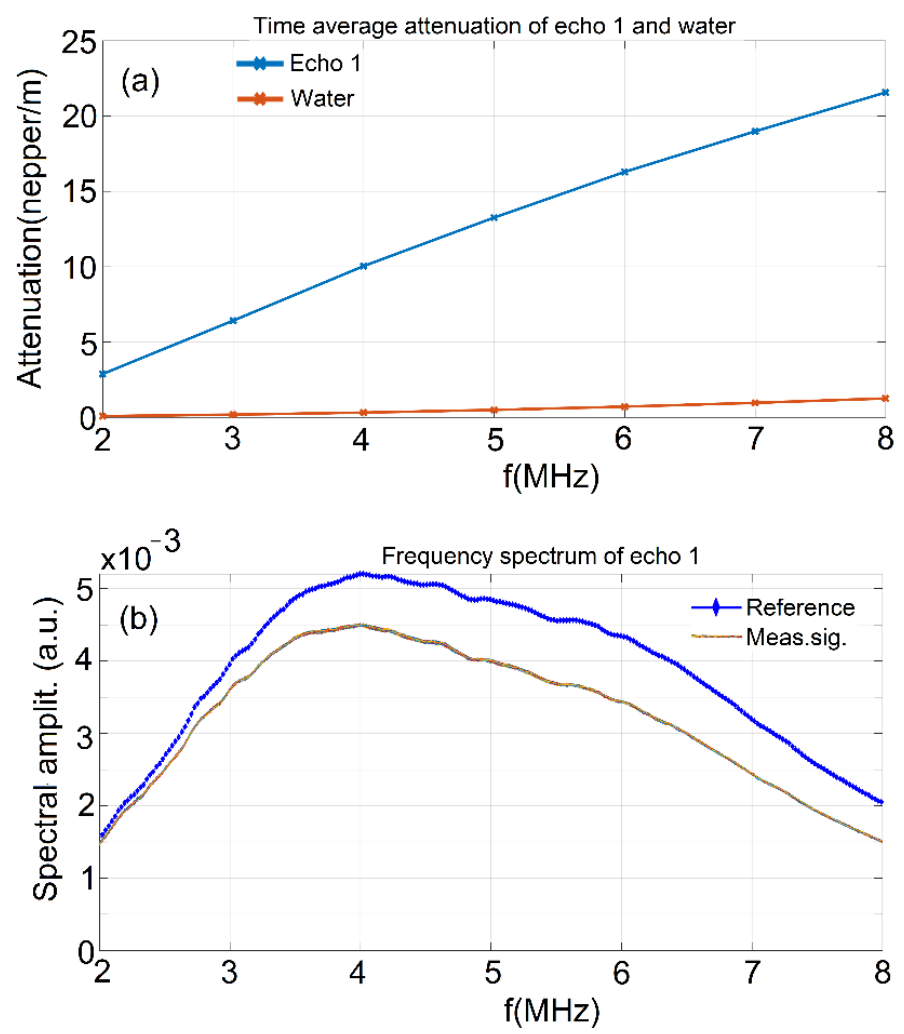

Figure 2. Spectral amplitude as a function of frequency for the suspension of 50SmHAp in relation to reference fluid (a) and Relative spectral amplitudes as a function of frequency (b).
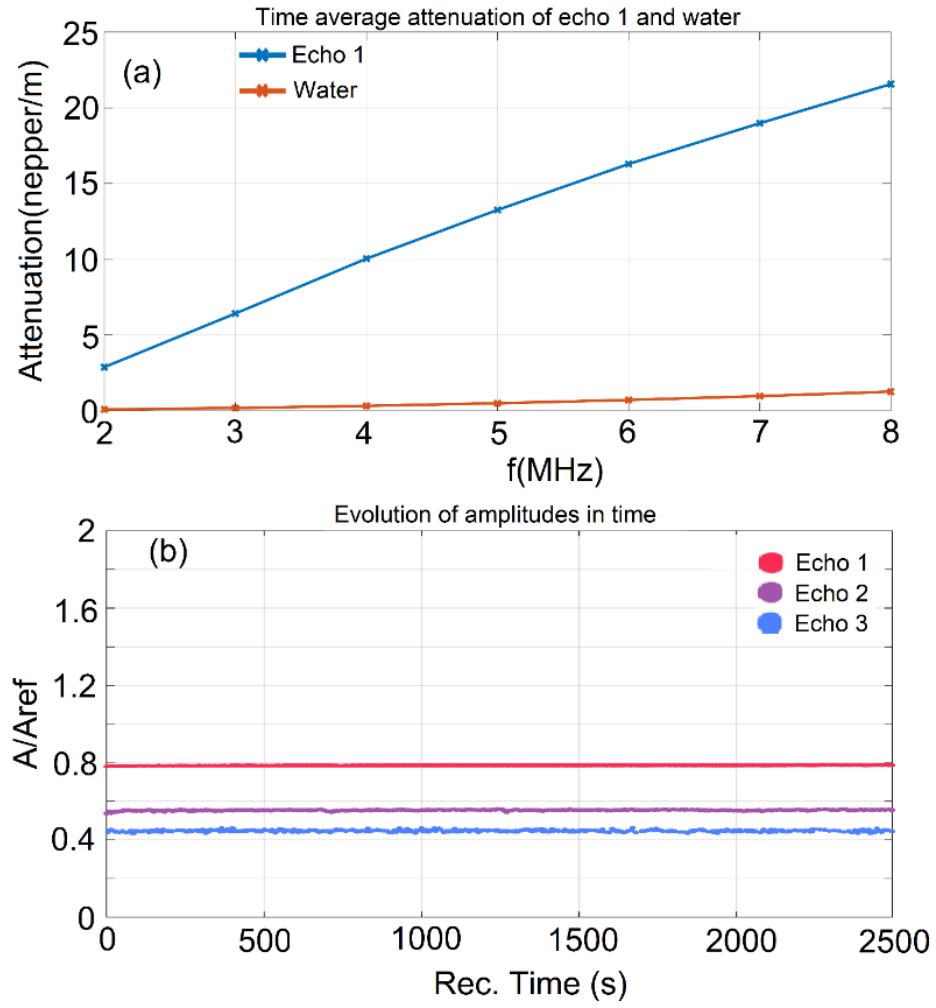

Figure 3. Attenuation vs. frequency for echo 1 of the 50SmHAp suspension and reference fluid (a) and relative spectral amplitudes as a function of time (b). 

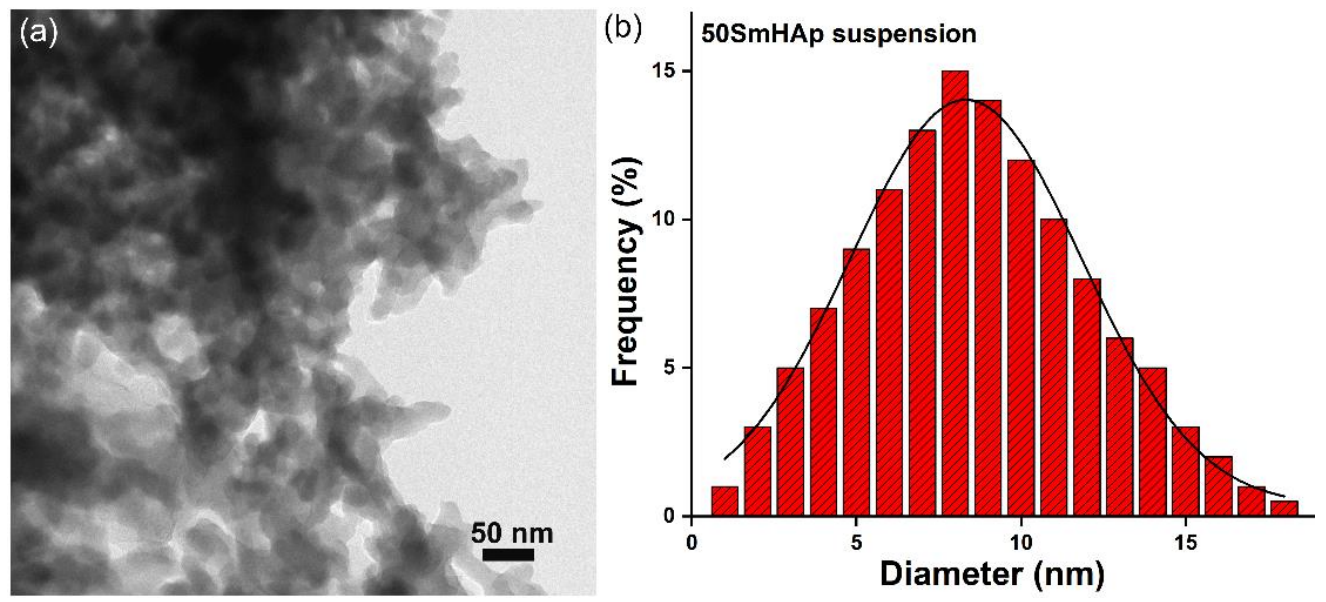

Figure 4. TEM micrographs (a) and particle size distribution of 50SmHAp suspension (b).

The morphology and chemical composition of both samples (50SmHAp suspension and coating), were analyzed using a scanning electron microscope (SEM) coupled with an EDX (energy dispersive X-ray) device. Figure $5 \mathrm{a}, \mathrm{b}$ shows the SEM images together with the average particle size obtained on the 50SmHAp suspension. The SEM image (Figure 5a) shows that the 50SmHAp suspension is made up of nanometric particles with an elongated morphology and with a pronounced agglomeration tendency. Also, for the 50SmHAp suspension (Figure $5 \mathrm{~b}$ ), an average particle size of $9 \pm 1 \mathrm{~nm}$ was obtained (estimated from SEM measurements).
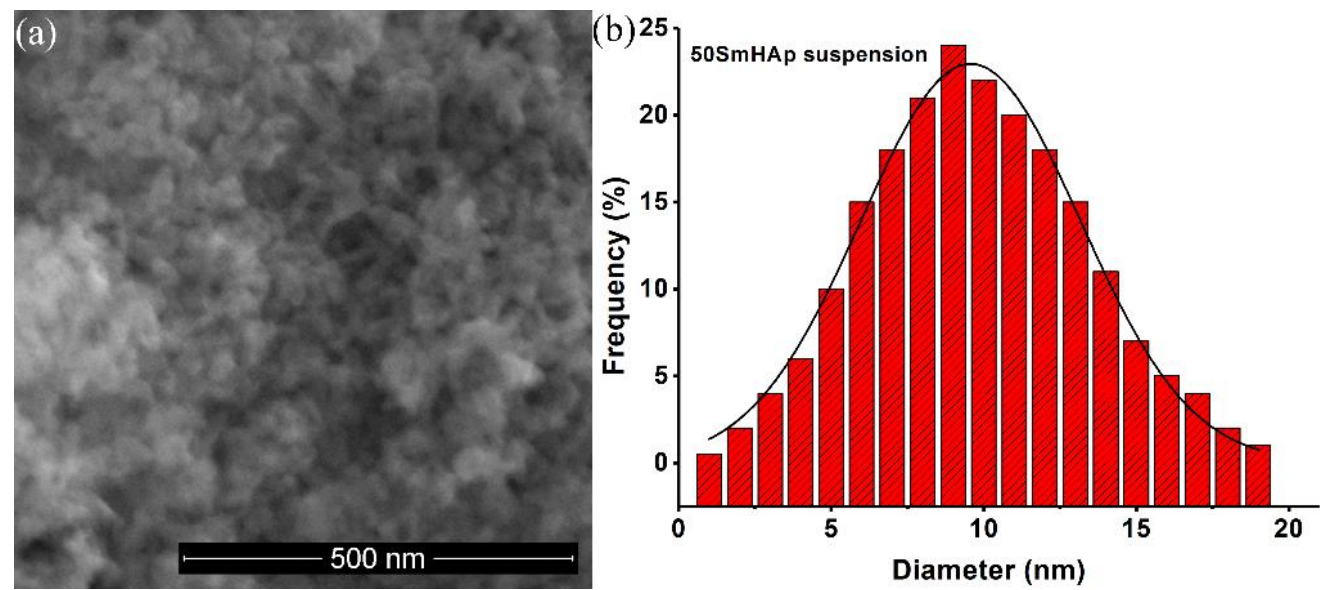

Figure 5. SEM image (a) and particle size distribution (b) of 50SmHAp suspension.

In the Figure $6 \mathrm{a}-\mathrm{c}$ the SEM micrographs are revealed, in addition to the coating thickness with the EDS spectra characteristic to the 50SmHAp coatings. The SEM micrographs obtained on the studied coating shows that their surface is nanostructured, continuous, uniform without the presence of fissures or other noticeable defects (Figure 6a). Also, the EDS spectra confirms on the one hand the presence of Ca, P, O and Sm in the samples and on the other hand the purity of the analyzed coatings is highlighted. The $\mathrm{Si}$ line from the EDS spectra (Figure 6c) arise from the Si substrate. The thickness of the thin films was determined from the cross-section image analyzed by scanning electron microscopy as presented in Figure $6 \mathrm{~b}$. The thickness of the composite layers was obtained from 10 individual measurements and presented as mean \pm SD. The measurements of the coatings thickness were done using Image J software [40]. The results revealed that the NBrHAp coatings thickness was approximately $97.51 \pm 9.03 \mathrm{~nm}$. 

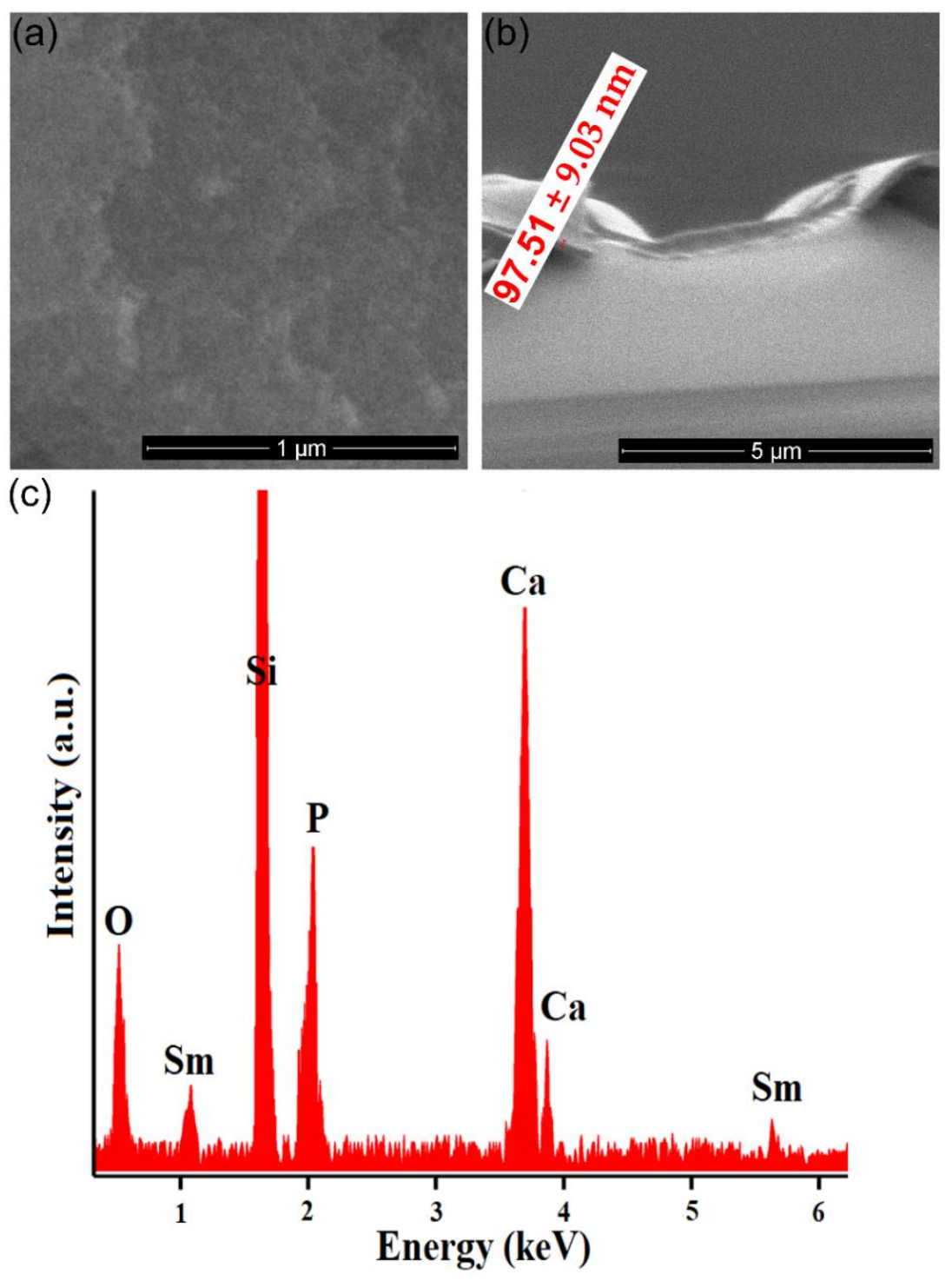

Figure 6. SEM micrographs (a) coating thickness (b) and EDS spectra (c) characteristics of the 50SmHAp coatings.

Furthermore, the surface topography of the 50SmHAp coatings was analyzed using atomic force microscopy. The results of the AFM studies are showed in Figure 7. Thus, the presence of well-distributed nanoagglomerates can be observed as well as the continuity of the coatings. Also, the uniformity of the coatings is highlighted both in the 2D AFM images and in their 3D representation. At the same time, the roughness ( $\mathrm{R}_{\mathrm{RMS}}$ ) of the 50SmHAp layers deposited on the Si substrate, obtained following the AFM studies was $9.87 \mathrm{~nm}$.

Additional information regarding the 50SmHAp coatings surface morphology was obtained with the aid of metallographic microscopy. Both representation (2D and 3D) of the surface morphology specific to the 50SmHAp coatings are presented in Figure 8. Our results, suggest that the coatings are continuous and without defects. Therefore, our results obtained by three different microscopic methods (SEM, AFM and metallographic microscopy) used to study the topography/morphology of the 50SmHAp coating surfaces are in good agreement suggesting the obtaining of a uniform and continuous coatings (with no evidence of surface defects). 

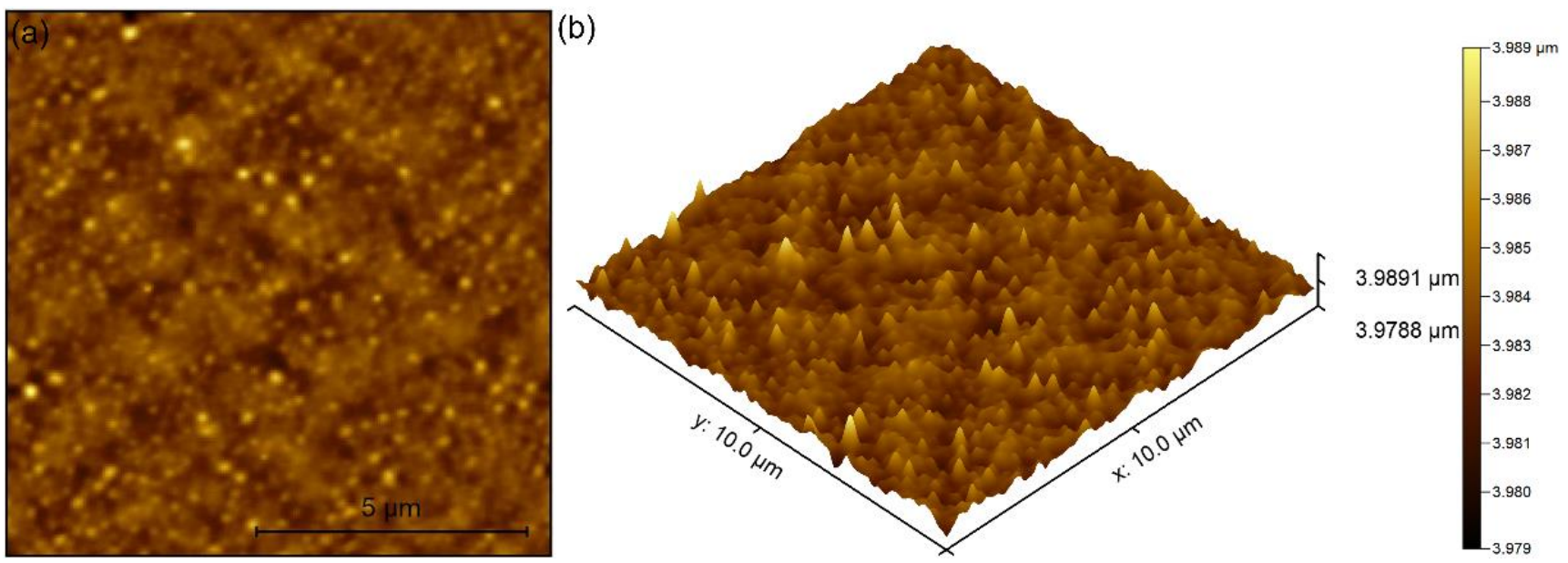

Figure 7. Typical 2D (a) and 3D (b) AFM images of surface topography obtained on 50SmHAp coatings deposited on Si substrate.
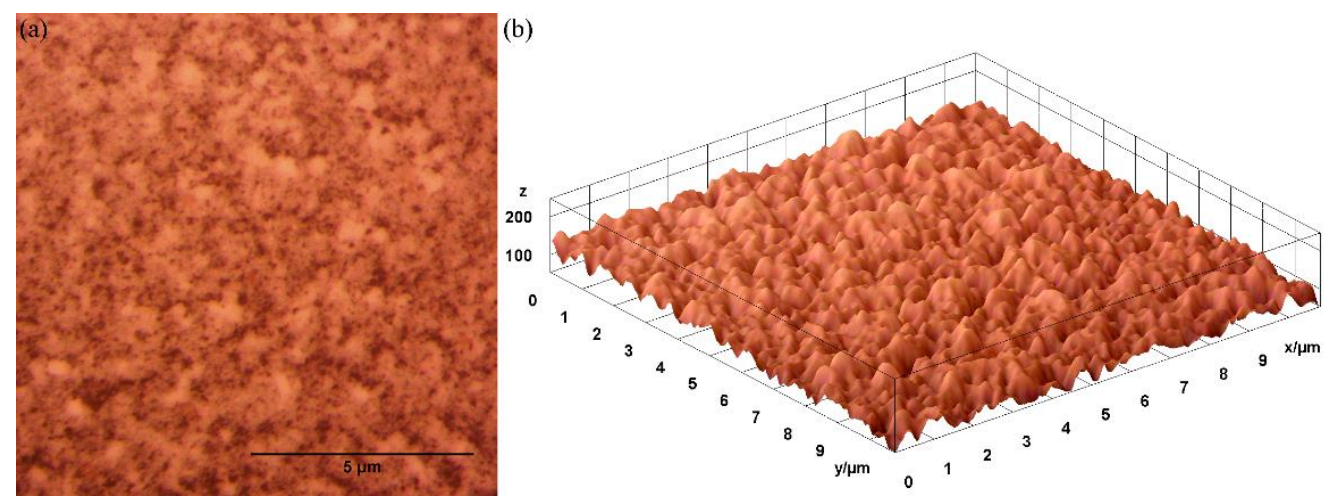

Figure 8. 2D Optical micrograph (100 $\times$ total magnification) of the 50SmHAP coatings microstructure (a) and their $3 \mathrm{D}$ representation $(\mathbf{b})$.

The presence and the identification of the main vibrational bands specific to the hydroxyapatite structure was performed with the aid of infrared spectroscopy. In the Figure 9 are presented the specific absorbance spectra deconvoluted in the $450-700 \mathrm{~cm}^{-1}$ and $900-1200 \mathrm{~cm}^{-1}$ spectral regions obtained for 50SmHAp coatings (a,b) and suspension (c,d).

For a better identification of molecular species from the 50SmHAp suspensions and coatings, the deconvolution of the vibrational bands presented in the $450-700 \mathrm{~cm}^{-1}$ and 900-1200 $\mathrm{cm}^{-1}$ spectral domains was performed. After the deconvolution of FTIR spectra, four subbands were obtained for $450-700 \mathrm{~cm}^{-1}$ spectral region and six subbands for $900-1200 \mathrm{~cm}^{-1}$ domain. In the case of 50SmHAp coatings the vibrational subbands specific to $v_{4}\left[\mathrm{PO}_{4}\right]^{3-}$ from HAp structure are found at: $538 \mathrm{~cm}^{-1} ; 566 \mathrm{~cm}^{-1}$; $603 \mathrm{~cm}^{-1}$ (Figure 9a) $[11,12,41]$. Meanwhile the subbands typical for the $v_{3}\left[\mathrm{PO}_{4}\right]^{3-}$ were noticed at: $1030 \mathrm{~cm}^{-1} ; 1034 \mathrm{~cm}^{-1} ; 1045 \mathrm{~cm}^{-1} ; 1066 \mathrm{~cm}^{-1} ; 1093 \mathrm{~cm}^{-1}$ and $1100 \mathrm{~cm}^{-1}$ (Figure 9b) [11,12,41]. The main vibrational band found at $961 \mathrm{~cm}^{-1}$ can be attributed to the $v_{1}\left[\mathrm{PO}_{4}\right]^{3-}$ from the HAp structure. Also, the broadened band observed at $473 \mathrm{~cm}^{-1}$ belongs to $v_{2}\left[\mathrm{PO}_{4}\right]^{3-}$. Moreover, for the 50SmHAp suspension, the position of subbands specific to $v_{4}\left[\mathrm{PO}_{4}\right]^{3-}$ from HAp structure are at: $539 \mathrm{~cm}^{-1} ; 567 \mathrm{~cm}^{-1} ; 603 \mathrm{~cm}^{-1}$ (Figure 9c) $[11,12,41]$. In the $450-700 \mathrm{~cm}^{-1}$ spectral region, could be noticed the presence of a weak peak at $475 \mathrm{~cm}^{-1}$ assigned to $v_{2}\left[\mathrm{PO}_{4}\right]^{3-}$ from HAp structure. The subbands presented at: $1031 \mathrm{~cm}^{-1} ; 1033,1046 \mathrm{~cm}^{-1} ; 1068 \mathrm{~cm}^{-1} ; 1095 \mathrm{~cm}^{-1}$ and $1101 \mathrm{~cm}^{-1}$ could be assigned to $v_{3}\left[\mathrm{PO}_{4}\right]^{3-}$ (Figure 9d) $[11,12,41]$. Furthermore, the shoulder from $962 \mathrm{~cm}^{-1}$ is typical $v_{1}\left[\mathrm{PO}_{4}\right]^{3-}$ from the HAp structure. 

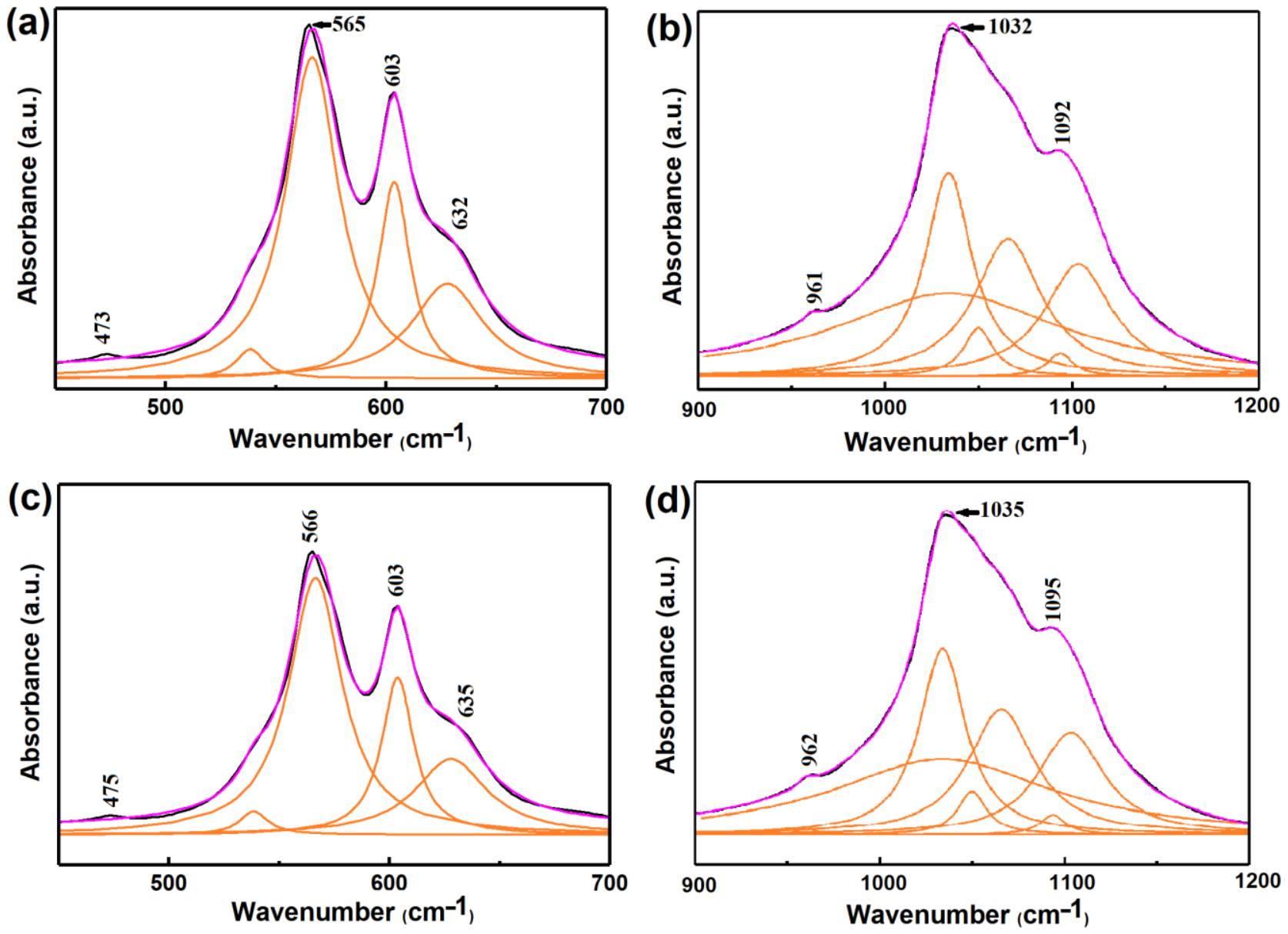

Figure 9. Specific absorbance spectra deconvoluted in the $450-700 \mathrm{~cm}^{-1}$ and $900-1200 \mathrm{~cm}^{-1}$ spectral region obtained for 50SmHAp coatings $(\mathbf{a}, \mathbf{b})$ and suspension $(\mathbf{c}, \mathbf{d})$. The experimental curve is plotted in purple and calculated theoretical bands are in orange.

Information regarding the presence of the vibrational bands specific to $v_{1}, v_{2}, v_{3}$ and $v_{4}\left[\mathrm{PO}_{4}\right]^{3-}$ vibration in the 50SmHAp structure were revealed in the Figure 10. In Figure 10 are presented the infrared absorbance spectra along with the second derivative spectra obtained in the spectral regions characteristic to the $v_{1}, v_{2}, v_{3}$ and $v_{4}\left[\mathrm{PO}_{4}\right]^{3-}$ vibration (from the HAp structure) for the 50SmHAp coatings $(\mathrm{a}-\mathrm{c}$ ) and suspensions $(\mathrm{d}-\mathrm{f})$.

In the following, will be discussed the results obtained in the case of 50SmHAp suspensions (Figure 10d-f). First of all, we noticed that the broadened symmetric $v_{1}$ $\left(\sim 473 \mathrm{~cm}^{-1}\right)$ and $v_{2}\left(\sim 961 \mathrm{~cm}^{-1}\right)$ bands of $\left[\mathrm{PO}_{4}\right]^{3-}$ are no split. The presence of $v_{\mathrm{L}}\left[\mathrm{OH}^{-}\right]$ band in the second derivative spectra at about $632 \mathrm{~cm}^{-1}$ shows that the $50 \mathrm{SmHAp}$ structure is well crystallized [34]. Furthermore, the vibrational band observed at $564,603 \mathrm{~cm}^{-1}$ are typical to $v_{4}\left[\mathrm{PO}_{4}\right]^{3-}$ bands from the hydroxyapatite structure (Figure 10e) $[11,12,41]$. At the same time, in the specific spectral region of $\mathrm{v}_{3}\left[\mathrm{PO}_{4}\right]^{3-}$ bands the presence of 3 peaks can be observed $\left(\sim 1032, \sim 1063\right.$ and at $\left.\sim 1100 \mathrm{~cm}^{-1}\right)$ (Figure 10f) [11,12,41]. In the second derivative spectra obtained for the 50SmHAp coatings could be noticed a slight displacement of the vibration bands accompanied by their increase in intensity compared to the spectra obtained on 50SmHAp suspensions. 

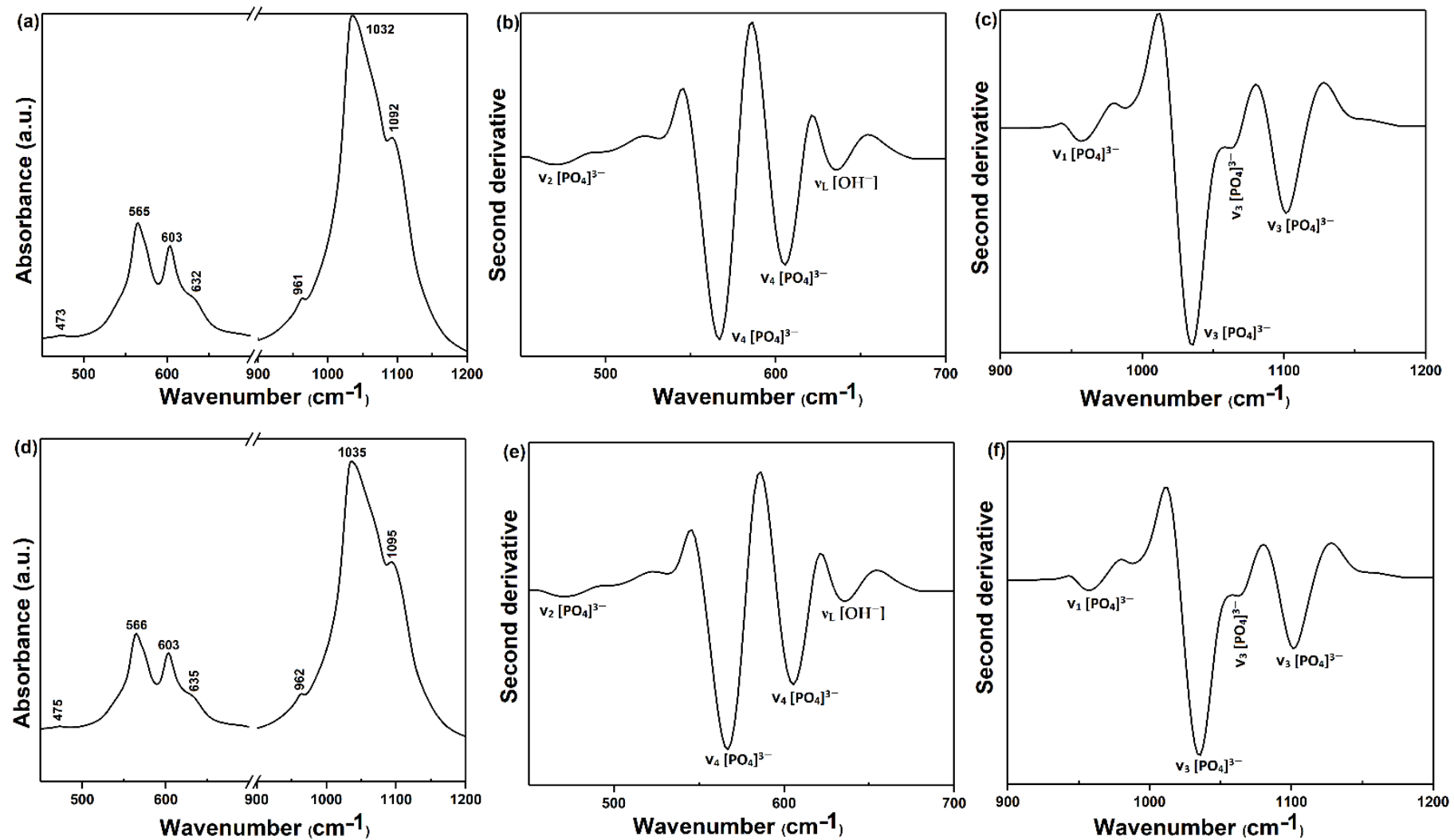

Figure 10. Infrared spectra and the obtained second derivative profiles in the $450-700 \mathrm{~cm}^{-1}$ and $900-1200 \mathrm{~cm}^{-1} \mathrm{spectral}$ regions for 50SmHAp coatings $(\mathbf{a}-\mathbf{c})$ and suspensions $(\mathbf{d}-\mathbf{f})$.

The results of the FTIR studies conducted on 50SmHAp suspensions and coatings by the absence of additional vibrational bands highlighted the samples purity. In our previous work, conducted on SmHAp coatings $\left(\mathrm{x}_{\mathrm{Sm}}=0.05\right)$ obtained by rf magnetron sputtering technique, we have highlighted the presence of main vibrational band associated to phosphate and hydroxyl group from the apatitic structure [12]. Moreover, in the case of SmHAp coatings $\left(\mathrm{x}_{\mathrm{Sm}}=0.05\right)$ synthesized by sol-gel process using the dip coating method, in the FTIR spectra was noticed that the vibration bands are more intense in the case of coatings compared to suspensions [11]. Also, a slight displacement of the vibrational bands was observed for the SmHAp coatings $\left(\mathrm{x}_{\mathrm{Sm}}=0.05\right)$ [11]. Therefore, we could suggest that our results are in good agreement with the ones reported for the samples prepared by similar method.

Recent studies have shown that Glow discharge optical emission spectroscopy (GDOES) can be used successfully with enormous potential for the study in depth profile of very thin films (conducting or non-conducting) that have a thickness of less than $10 \mathrm{~nm}$ [50]. In this study the glow discharge optical emission spectroscopy (GDOES) has been used in order to establish the distribution from surface to the substrate interface of the chemical components presents in the 50SmHAp thin film. The elementary GDOES depth profiles of the 50SmHAp thin film deposited on the silicon substrate were shown in Figure 11. It is observed that the layer was composed of samarium, hydrogen, oxygen, phosphorus and calcium. The observed silicium comes from the substrate of the sample. It is observed that the interface zone between the Si substrate and 50SmHAp thin film was highlighted by the brusque increase in the depth profile of Si. Moreover, in the area delimiting the interface between the Si substrate and the 50SmHAp thin film, maxima were observed on the curves representing $\mathrm{Ca}, \mathrm{P}$ and $\mathrm{Sm}$. At the same time, a decrease in the depth profile curves for $\mathrm{O}$ and $\mathrm{H}$ was observed in this interface area. 


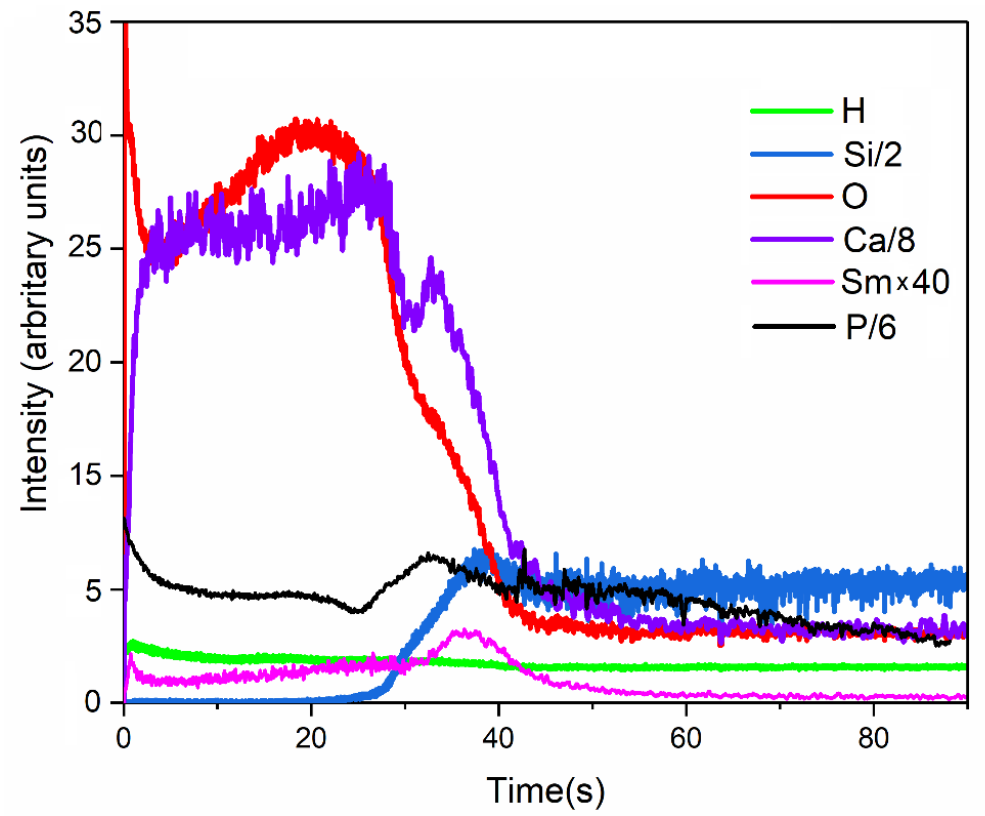

Figure 11. Depth profile of 50SmHAp coating on Si substrate obtained using spin coating method.

The behavior of the depth profile curves representing the constituent elements of the obtained 50SmHAp thin film and that of Si (representing the substrate) was similar to that of the depth profile curves for the 5SmHAp coatings realized by radio frequency magnetron sputter which was presented in a previous study [27]. In the case of the 50SmHAp thin film obtained by spin coating method, it was observed that the area representing the interface between the Si substrate and the thin film shifted to lower time values compared to the studied 5SmHAp coatings. This behavior is given by the thickness of the layer. The 50SmHAp thin film obtained by the spin coating method being thinner than the 5SmHAp coating obtained by rf magnetron sputtering [50]. The increase of the Sm content in the interlayer area could be due on the one hand to the substrate that presents non-uniformities corroborated with the deposition process used as well as to the heat treatment to which the coating layer was subjected in order to have a good crystallinity [51]. The defects of the Si substrate were covered by the coating process, obtaining in the end a uniform surface. According to previous studies, controlling the sintering atmosphere plays an important role [52].These results of our studies confirm the sensitivity and accuracy of the GDOES method as well as the broad spectrum of application [52-54].

The antifungal properties of the 50SmHAp coatings on the adhesion and proliferation of C. albicans cells were investigated using SEM and CLSM techniques.

The development and adhesion of the fungal cells on the surfaces of 50SmHAp coatings were studied at different incubation time, $(24,48$ and $72 \mathrm{~h})$. The results of the SEM visualization of the fungal cells adhered on the surfaces of the 50SmHAp coatings after 24, 48 and $72 \mathrm{~h}$ of incubation are presented in Figure 12a,c,e. The SEM images depicted that the adhered fungal cells morphology is characteristic to $C$. albicans fungal strain, with round-to-oval shapes and sizes ranging from 2.42 to $4.74 \mu \mathrm{m}$. The results of the SEM studies have revealed that the 50SmHAp coatings were effective in inhibiting the adherence and fungal cells development after $24 \mathrm{~h}$ of incubation and did not allowed the development of fungal biofilms. After $24 \mathrm{~h}$ of incubation only several conglomerates of fungal cells were detected on the surface of the 50SmHAp coatings. Moreover, the studies also shown that the 50SmHAp coatings inhibited the development of C. albicans fungal biofilms. Furthermore, the data suggested that the antifungal effects of the 50SmHAp coatings are correlated with the incubation interval by clearly evidencing that the number of fungal cells present on the 50SmHAp coatings significantly decreased. The results concluded that the C. albicans fungal cells numbers was considerably reduced after 48 and $72 \mathrm{~h}$ of incubation with the 50SmHAp 
coatings. In addition, the SEM analysis revealed that 50SmHAp coatings prevented the formation of fungal biofilms on their surfaces. More than that, after $72 \mathrm{~h}$ of incubation the number of fungal adhered cells was insignificant. Furthermore, the 3D representation of the SEM images obtained using Image J software (Image J 1.51j8) [40] are also depicted in Figure $12 b, d, f$.
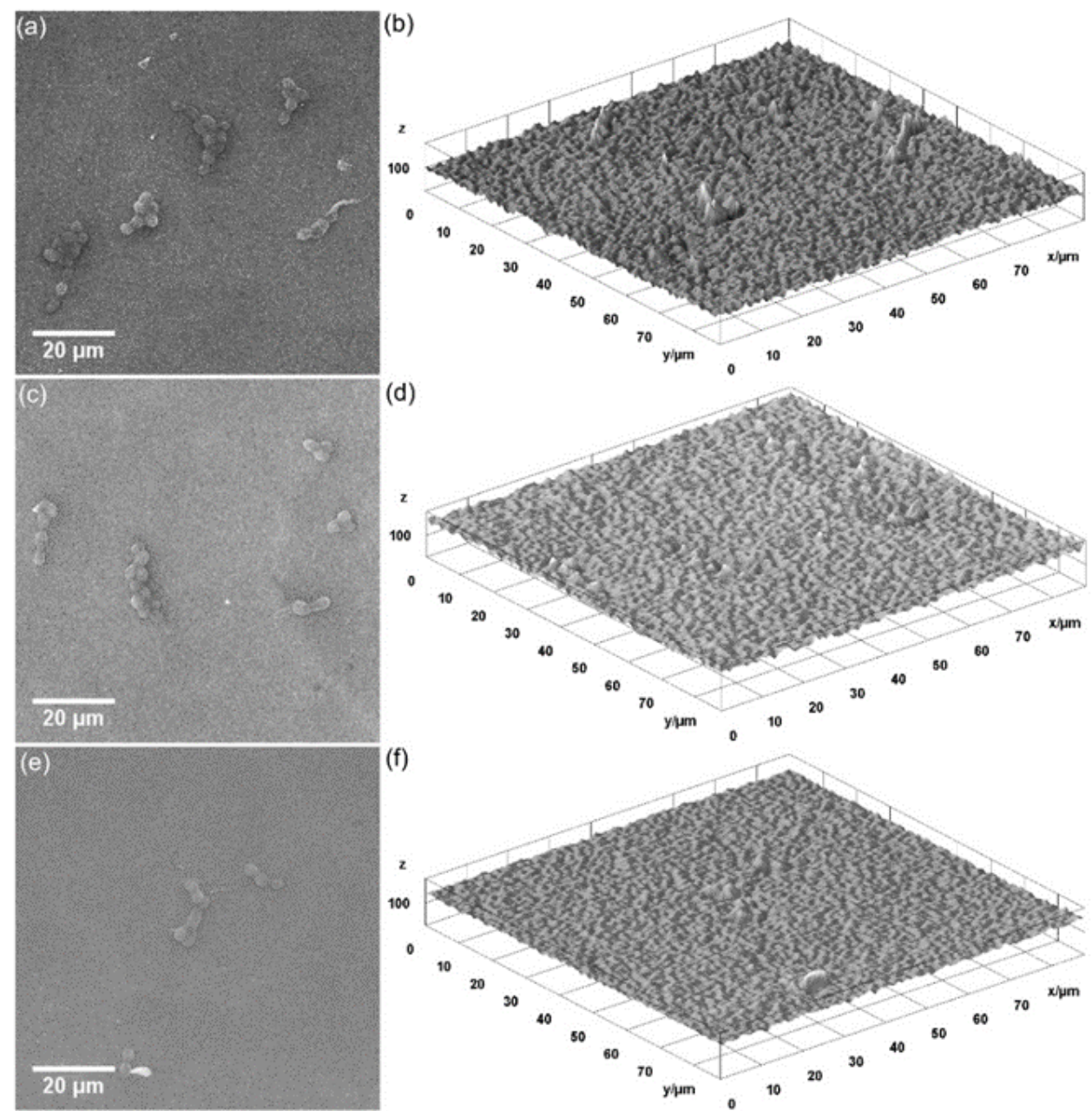

Figure 12. 2D SEM images and 3D representation of Candida albicans ATCC 10231 cell development on 50SmHAp coatings after $24 \mathrm{~h} \mathrm{(a,b),} 48 \mathrm{~h}(\mathbf{c}, \mathbf{d})$ and $72 \mathrm{~h}(\mathbf{e}, \mathbf{f})$ of incubation.

The results of the SEM visualization have determined that the 50SmHAp coatings presented good antifungal activity which could be attributed to the presence of samarium ions from the HAp lattice. In our previous studies regarding the activity of 5SmHAp coatings reported by C.S. Ciobanu et al. in [11], the results have emphasized that simple HAp coatings helped the development of the fungal cells and also promoted their proliferation and boosted the formation of a fungal biofilm, therefore supporting the hypothesis of samarium ions been responsible for the antimicrobial effects of the 50SmHAp coatings.

Furthermore, qualitative assays regarding the development and adhesion of $C$. albicans fungal cells on the surface of 50SmHAp coatings were also undergo using CLSM studies. The CLSM images of the fungal cells attachment on the 50SmHAp coatings surfaces after 24, 48 and $72 \mathrm{~h}$ of incubation are presented in Figure 13a-f. 

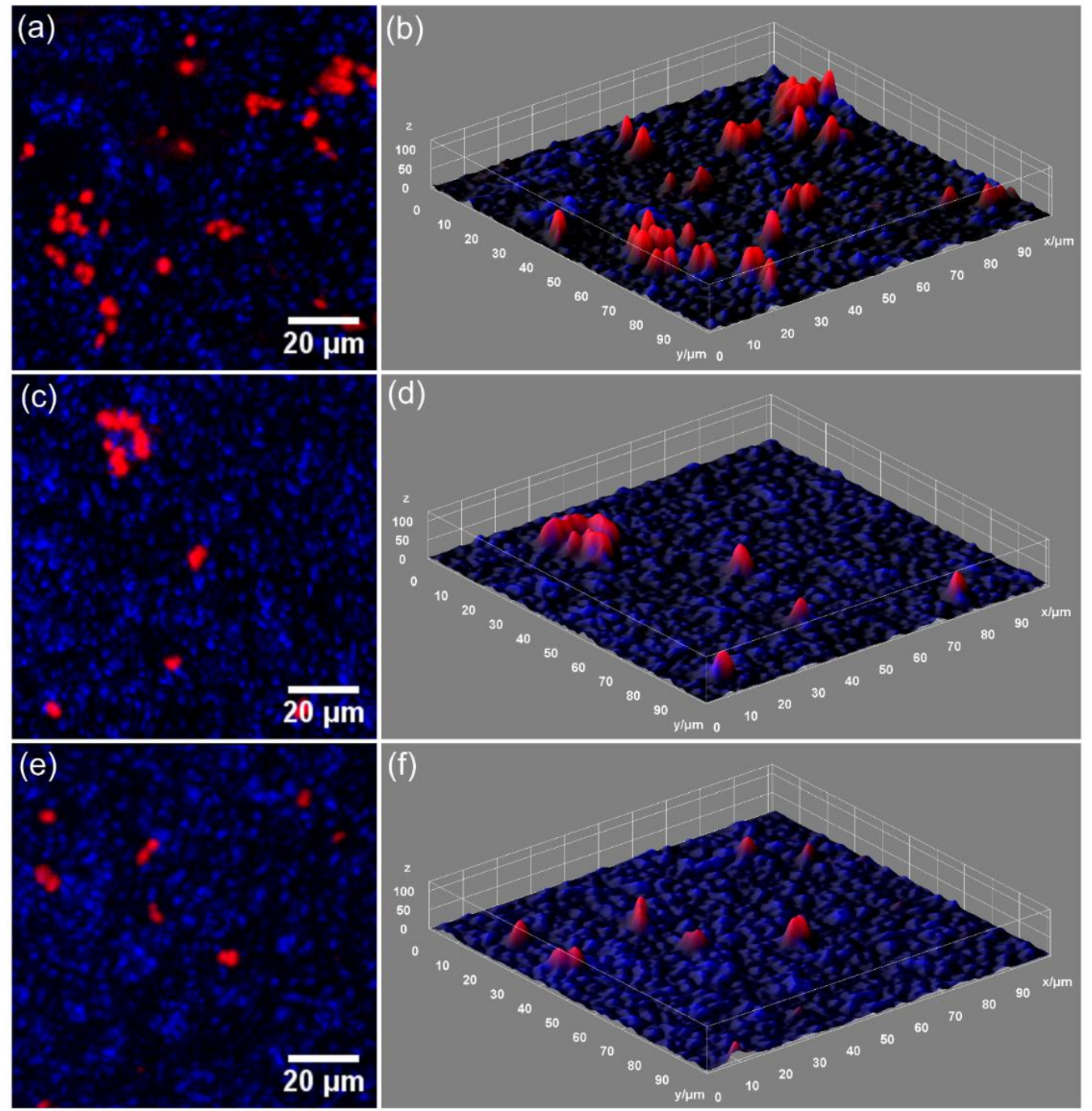

Figure 13. 2D CLSM images and 3D representation of the CLSM images of Candida albicans ATCC 10231 adhesion on 50SmHAp coatings deposited on Si after $24 \mathrm{~h}(\mathbf{a}, \mathbf{b}), 48 \mathrm{~h}(\mathbf{c}, \mathbf{d})$ and $72 \mathrm{~h}(\mathbf{e}, \mathbf{f})$ of incubation.

The CLSM studies have emphasized that the 50SmHAp coatings were effective in blocking the C. albicans cell development and proliferation and also in preventing the biofilm formation for all tested time intervals. The results of the CLSM visualization depicted in Figure 13a,c,e highlighted that the 50SmHAp effectively inhibited the fungal cells development after $24 \mathrm{~h}$ of incubation. The CLSM visualization depicted in Figure 13 evidenced that the cells attached on the surface of the 50SmHAp coatings were scarce distributed and do not present any major conglomerates. In addition, the CLSM images illustrate that the fungal cells attached to the 50SmHAp coatings were distinctive to C. albicans, presenting an ovaloid cell morphology and sizes from 2.19 to $4.53 \mu \mathrm{m}$. The results depicted in Figure 13a,c,e, also emphasized that the antifungal properties of the 50SmHAp coatings were influenced by the time of incubation. Moreover, the CLSM visualization confirmed the SEM results and evidenced that the 50SMHAp were effective in inhibiting the $C$. albicans cell development on their surface and preventing biofilm formation. Also, the results have confirmed that after $72 \mathrm{~h}$ of incubation the number of fungal cells still adhered on the surface of 50SmHAp coatings are considerably diminished, almost to extinction. In addition, the 3D representation of the CLSM images are also presented in Figure 13b,d,f. The 3D representation obtained using Image J software [40] show the structure and spatial distribution of the C. albicans fungal cells on the surface of 50SmHAp 
coatings after different time incubation periods. The images depict the spatial distribution of the ovaloid shaped fungal cells (red color) on the 50SmHAp coating's surface. The 3D representation of the CLSM images also suggested that the development of the fungal cells have been considerably decreased and that their inhibition was influenced by the incubation time period. The results obtained by the qualitative antifungal assays concluded that these coatings could be of great interest in the future development of antifungal coatings for medical devices.

Furthermore, the quantitative antifungal assays of the 50SmHAp suspensions and coatings were also performed using C. albicans ATCC 10231 fungal strain. The results depicting the graphical representation of the effects of 50SmHAp suspensions and coatings on the development of $C$. albicans ATCC 10231 colony-forming units (CFU) at three different time intervals $(24,48$ and $72 \mathrm{~h})$ are presented in Figure 14.

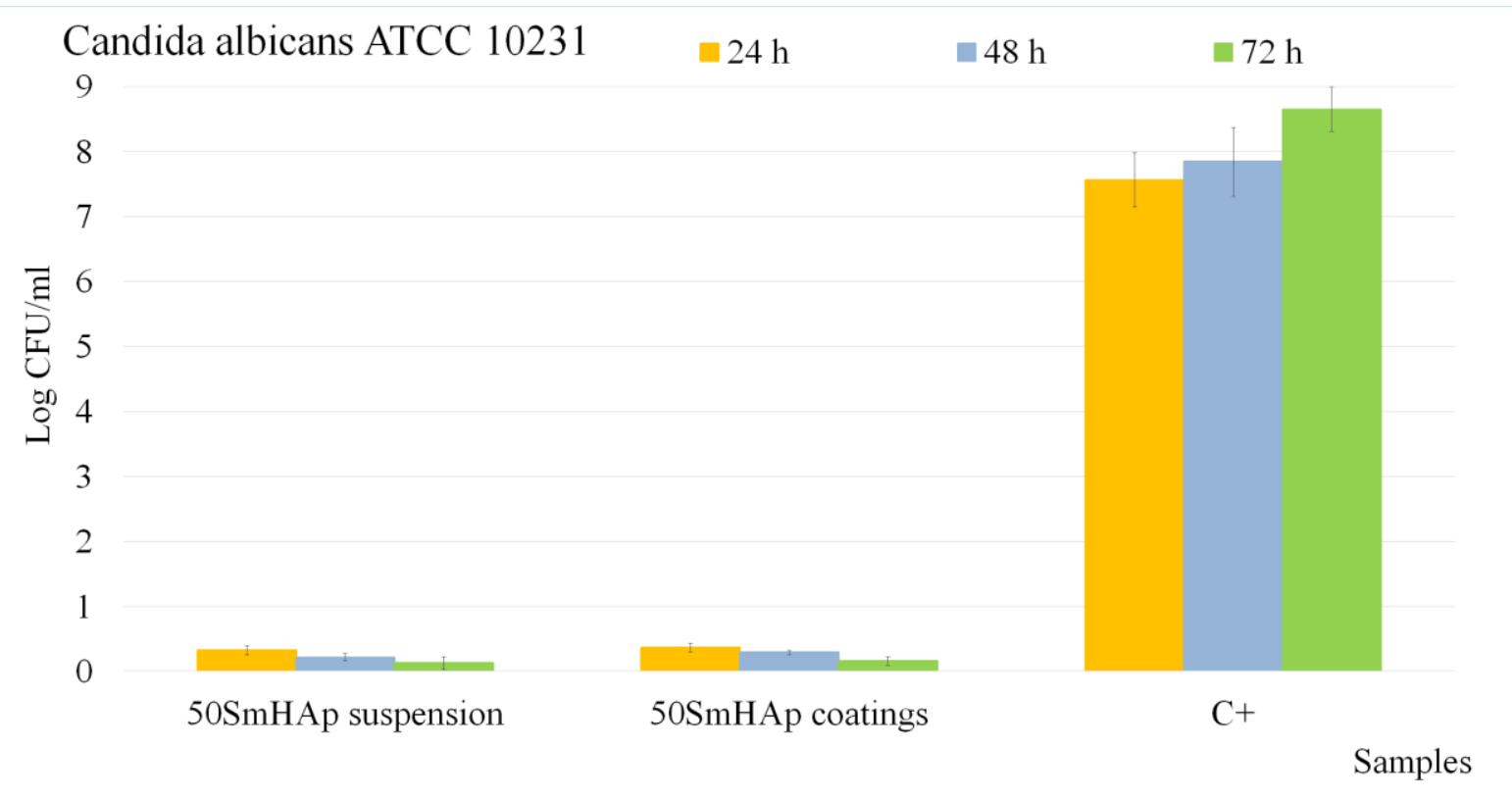

Figure 14. The effect of the 50SmHAp suspension and coatings on the Candida albicans cell development at different time incubation periods.

The data suggested that the fungal CFU's development was inhibited from the first phase of adherence for both suspensions and coatings. The colony forming unit count (CFUc) assay highlighted that there is a significant reduction in the number of colonies after $24 \mathrm{~h}$ for both 50SmHAp suspensions and coatings compared to the number of colonies formed in the case of the positive control culture $(\mathrm{C}+)$. More than that, the results showed that the antifungal activity of both suspensions and coatings was correlated with the incubation period. In addition, the quantitative assays also revealed that the antifungal activity of 50SmHAp suspensions was higher than that of 50SmHAp coatings for all tested intervals. Moreover, the data strongly suggested that after $72 \mathrm{~h}$ both the suspensions and the coatings effectively inhibit the fungal cell development and significantly reduces the number of $\mathrm{CFU}$, almost near extinction. The results are in good agreement with the data obtained from the qualitative assays and also with the existing studies reported in the literature regarding the antimicrobial effects of samarium ions $[10,11,14,55-59]$. The antifungal activity of the suspensions was also assessed in order to establish if the deposition method allows the coatings to preserve the antifungal activity of the suspensions used for their obtaining. The results of the quantitative assays emphasized that the 50SmHAp coatings retain almost in totality the antifungal effects of the suspensions used for their depositions. These findings are in agreement with previous reported studies $[10,11]$ and strengthen the proposed aim 
of this study, that, of proving that an adapted co-precipitation method is adequate to obtain stabile suspensions for the fabrication of samarium doped hydroxyapatite thin films with antifungal properties by spin-coating technique.

The influence of the incubation time on the antifungal effect of both the suspensions and coatings could also be attributed to the gradual release of samarium ions from the HAp lattice. One of the proposed samarium ions antimicrobial mechanisms was due to the fact that samarium ions have the ability to change the fungal cell membrane permeability by attaching to it and affecting in the process the fungal cell's adhesion, ion conductivity and cell signaling [14]. More than that, both Barry et al. and Ferraris et al. $[60,61]$ reported in their studies that the nature of the substrate could influence the biological properties of the samples. In addition, the studies showed that not only the composite and/or substrate are responsible for the biological properties of the coatings but also the synergic connections that appear between the substrate and the thin layer [60,61].

The data obtained from the in vitro antifungal assays are in agreement with previous reported studies and highlighted that both 50SmHAp suspensions and coatings present strong antifungal properties, that are influenced by the incubation time. The results of the qualitative assays conducted by SEM and CLSM observation, evidenced that the adhesion and development of $C$. albicans fungal cells was greatly inhibited by the samarium doped composites suspensions and coatings. Moreover, the SEM and CLSM visualization also emphasized that the 50SmHAp coatings have prevented the fungal biofilm formation. Therefore, the results suggested that the development of novel 50SmHAp suspensions and coatings could be promising candidates for the obtaining of novel antifungal medical devices.

\section{Conclusions}

The goal of this analysis was to establish that spin-coating route is suitable for the preparation of $\left(\mathrm{Ca}_{10-\mathrm{x}} \mathrm{Sm}_{\mathrm{x}}\left(\mathrm{PO}_{4}\right)_{6}(\mathrm{OH})_{2}, \mathrm{x}_{\mathrm{Sm}}=0.5,50 \mathrm{SmHAp}\right)$ on $\mathrm{Si}$ substrate. The amplitudes of signals of the three recorded echoes, relative to the corresponding echoes of the reference fluid highlight the stability over time of the 50SmHAp suspension. The results obtained by the 3 microscopic methods (SEM, AFM and metallographic microscopy) used to study the topography/morphology of the 50SmHAp coating surfaces are in good agreement, suggesting the obtaining of a uniform and continuous coating (with no evidence of surface defects). The presence of the vibrational bands specific to $v_{1}, v_{2}, v_{3}$ and $v_{4}$ $\left[\mathrm{PO}_{4}\right]^{3-}$ vibration in the 50SmHAp structure were revealed by FTIR studies. The elementary GDOES depth profiles of the 50SmHAp thin film deposited on the silicon substrate highlighted that the layers were composed of samarium, hydrogen, oxygen, phosphorus and calcium.

The results of the quantitative antifungal assay revealed that both 50SmHAp coatings and suspensions were effective in inhibiting the development of $C$. albicans fungal cells. Furthermore, the results of the qualitative assays by SEM and CLSM visualization of the C. albicans fungal cell development and adherence on the coatings surface evidenced that the coatings inhibited the cell development and also that they prevented biofilm formation. In addition, the data also suggested that the antifungal properties of both the suspensions and coatings were considerably influenced by the incubation time. The results obtained from the antifungal assays suggested that 50SmHAp suspensions and coatings could be considerate for future development of antifungal biomedical devices.

Author Contributions: Conceptualization, D.P., M.V.P., S.L.I., P.C. and C.S.C.; methodology, D.P., C.S.C., M.V.P., P.C. and S.L.I.; software, M.V.P.; validation, D.P., C.S.C., M.V.P., P.C. and S.L.I.; formal analysis, D.P., C.S.C., P.C., M.V.P. and S.L.I.; investigation, D.P., P.C., C.S.C., M.V.P. and S.L.I.; resources, D.P. and M.V.P.; data curation, D.P., C.S.C., M.V.P. and S.L.I.; writing-original draft preparation, D.P., C.S.C., M.V.P. and S.L.I.; writing-review and editing, D.P., C.S.C., M.V.P. and S.L.I.; visualization, D.P., P.C., C.S.C., M.V.P. and S.L.I.; supervision, D.P., C.S.C., M.V.P. and S.L.I.; project administration, D.P. and M.V.P.; funding acquisition, D.P. All authors have read and agreed to the published version of the manuscript. 
Funding: This work was supported by the Romanian Ministry of Research and Innovation through the project PN-III-P2-2.1-PED-2019-0868 contract No. 467PED/2020 and project PN-III-P2-2.1-PED2019-1375 contract No. 331/PED/2020.

Institutional Review Board Statement: Not applicable.

Informed Consent Statement: Not applicable.

Data Availability Statement: Not applicable.

Conflicts of Interest: The authors declare no conflict of interest; The funders had no role in the design of the study; in the collection, analyses, or interpretation of data; in the writing of the manuscript, or in the decision to publish the results.

\section{References}

1. Santos, M.H.; Valerio, P.; Goes, A.M.; Leite, M.F.; Heneine, L.G.; Mansur, H.S. Biocompatibility evaluation of hydroxyapatite/collagen nanocomposites doped with $\mathrm{Zn}^{+2}$. Biomed. Mater. 2007, 2, 135-141. [CrossRef] [PubMed]

2. Lin, K.; Chang, J. Structure and properties of hydroxyapatite for biomedical applications. In Hydroxyapatite (HAp) for Biomedical Applications; Mucalo, M., Ed.; Woodhead Publishing: Sawston, UK, 2015; pp. 3-19.

3. Sathishkumar, S.; Louis, K.; Shinyjoy, E.; Gopi, D. Tailoring the Sm/Gd-substituted hydroxyapatite coating on biomedical AISI 316L SS: Exploration of corrosion resistance, protein profiling, osteocompatibility, and osteogenic differentiation for orthopedic implant applications. Ind. Eng. Chem. Res. 2016, 55, 6331-6344. [CrossRef]

4. Kaygili, O.; Vural, G.; Keser, S.; Yahia, I.S.; Bulut, N.; Ates, T.; Koytepe, S.; Temuz, M.M.; Ercan, F.; İnce, T. Ce/Sm co-doped hydroxyapatites: Synthesis, characterization, and band structure calculation. J. Aust. Ceram. Soc. 2020, 57, 305-317. [CrossRef]

5. Zantye, P.; Fernandes, F.; Ramanan, S.R.; Kowshik, M. Rare earth doped hydroxyapatite nanoparticles for in vitro bioimaging applications. Curr. Phys. Chem. 2019, 9, 94-109. [CrossRef]

6. Dubnika, A.; Loca, D.; Rudovica, V.; Parekh, M.B.; Berzina-Cimdina, L. Functionalized silver doped hydroxyapatite scaffolds for controlled simultaneous silver ion and drug delivery. Ceram. Int. 2017, 43, 3698-3705. [CrossRef]

7. Hidalgo-Robatto, B.M.; López-Álvarez, M.; Azevedo, A.S.; Dorado, J.; Serra, J.; Azevedo, N.F.; González, P. Pulsed laser deposition of copper and zinc doped hydroxyapatite coatings for biomedical applications. Surf. Coat. Technol. 2018, 333, 168-177. [CrossRef]

8. Ciobanu, C.S.; Iconaru, S.L.; Popa, C.L.; Motelica-Heino, M.; Predoi, D. Evaluation of samarium doped hydroxyapatite, ceramics for medical application: Antimicrobial activity. J. Nanomater. 2015, 2015, 849216. [CrossRef]

9. Chen, P.; Wang, F.; Qiao, Y.; Zhang, Z. Luminescence of samarium doped hydroxyapatite containing strontium: Effects of doping concentration. J. Rare Earths 2021, in press. [CrossRef]

10. Iconaru, S.L.; Stanciu, G.A.; Hristu, R.; Ghita, R.V. Properties of Samarium doped hydroxyapatite thin films deposited by evaporation. Rom. Rep. Phys. 2017, 69, 508.

11. Ciobanu, S.C.; Iconaru, S.L.; Predoi, D.; Prodan, A.M.; Predoi, M.V. Physico-chemical properties and in vitro antifungal evaluation of samarium doped hydroxyapatite coatings. Coatings 2020, 10, 827. [CrossRef]

12. Iconaru, S.L.; Groza, A.; Gaiaschi, S.; Rokosz, K.; Raaen, S.; Ciobanu, S.C.; Chapon, P.; Predoi, D. Antimicrobial properties of samarium doped hydroxyapatite suspensions and coatings. Coatings 2020, 10, 1124. [CrossRef]

13. Nica, I.C.; Popa, M.; Marutescu, L.; Dinischiotu, A.; Iconaru, S.L.; Ciobanu, S.C.; Predoi, D. Biocompatibility and antibiofilm properties of samarium doped hydroxyapatite coatings: An in vitro study. Coatings 2021, 11, 1185. [CrossRef]

14. Morais, D.S.; Coelho, J.; Ferraz, M.P.; Gomes, P.S.; Fernandes, M.H.; Hussain, N.S.; Santos, J.D.; Lopes, M.A. Samarium doped glass-reinforced hydroxyapatite with enhanced osteoblastic performance and antibacterial properties for bone tissue regeneration. J. Mater. Chem. B 2014, 2, 5872-5881. [CrossRef] [PubMed]

15. Nabeel, A.I. Samarium enriches antitumor activity of $\mathrm{ZnO}$ nanoparticles via downregulation of CXCR4 receptor and cytochrome P450. Tumor Biol. 2020, 42, 1010428320909999. [CrossRef] [PubMed]

16. Kannan, S.; Nallaiyan, R. Anticancer activity of Samarium-coated magnesium implants for immunocompromised patients. ACS Appl. Bio Mater. 2020, 3, 4408-4416. [CrossRef]

17. Liu, Y.; Sun, Y.; Cao, C.; Yang, Y.; Wu, Y.; Ju, D.; Li, F. Long-term biodistribution in vivo and toxicity of radioactive/magnetic hydroxyapatite nanorods. Biomaterials 2014, 35, 3348-3355. [CrossRef] [PubMed]

18. Yuan, Q.; Wu, J.; Qin, C.; Xu, A.; Zhang, Z.; Lin, S.; Ren, X.; Zhang, P. Spin-coating synthesis and characterization of Zn-doped hydroxyapatite/polylactic acid composite coatings. Surf. Coat. Technol. 2016, 307, 461-469. [CrossRef]

19. Zavestovskaya, I.N.; Grigorieva, M.; Petrunya, D.; Grigoriev, A.; Deyev, S.M.; Prasad, P.N.; Kabashin, A.V. Novel advanced nanotechnologies for nuclear medicine. J. Phys. Conf. Ser. 2021, 2058, 012035. [CrossRef]

20. Popova-Kuznetsova, E.; Tikhonowski, G.; Popov, A.A.; Duflot, V.; Deyev, S.; Klimentov, S.; Zavestovskaya, I.; Prasad, P.N.; Kabashin, A.V. Laser-ablative synthesis of isotope-enriched samarium oxide nanoparticles for nuclear nanomedicine. Nanomaterials 2020, 10, 69. [CrossRef] 
21. Trujillo-Benítez, D.; Ferro-Flores, G.; Morales-Avila, E.; Jiménez-Mancilla, N.; Ancira-Cortez, A.; Ocampo-García, B.; SantosCuevas, C.; Escudero-Castellanos, A.; Luna-Gutiérrez, M.; Azorín-Vega, E. Synthesis and biochemical evaluation of samarium-153 oxide nanoparticles functionalized with iPSMA-bombesin heterodimeric peptide. J. Biomed. NanoTechnol. 2020, 16, 689-701. [CrossRef]

22. Eressa, L.A.; Rao, P.V.B. Electrical properties of praseodymium and samarium co-doped ceria electrolyte for low-temperature solid oxide fuel cell application. Bull. Mater. Sci. 2021, 44, 255. [CrossRef]

23. Zhu, Y.; Zhu, J.; Song, H.; Huang, J.; Lu, Z.; Pan, G. Samarium doping improves luminescence efficiency of $\mathrm{Cs}_{3} \mathrm{Bi}_{2} \mathrm{Br}_{9}$ perovskite quantum dots enabling efficient white light-emitting diodes. J. Rare Earths 2021, 39, 374-379. [CrossRef]

24. Leote, R.J.B.; Matei, E.; Apostol, N.G.; Enculescu, M.; Enculescu, I.; Diculescu, V.C. Monodispersed nanoplatelets of samarium oxides for biosensing applications in biological fluids. Electrochim. Acta 2021, 402, 139532. [CrossRef]

25. Rao, N.S.; Rajesh, M.; Prasad, K.; Reddy, G.R.; Raju, B.D.P.; Dhanapandian, S. Study of trivalent samarium ion embedded lithium-based borate glass for high-density optical memory devices. Luminescence 2020, 35, 721-727. [CrossRef] [PubMed]

26. Sygnatowicz, M.; Tiwari, A. Controlled synthesis of hydroxyapatite-based coatings for biomedical application. Mater. Sci. Eng. C 2009, 29, 1071-1076. [CrossRef]

27. Montenero, A.; Gnappi, G.; Ferrari, F.; Cesari, M.; Salvioli, E.; Mattogno, L.; Kaciulis, S.; Fini, M. Sol-gel derived hydroxyapatite coatings on titanium substrate. J. Mater. Sci. 2000, 35, 2791-2797. [CrossRef]

28. Huang, L.Y.; Xu, K.W.; Lu, J. A study of the process and kinetics of electrochemical deposition and the hydrothermal synthesis of hydroxyapatite coatings. J. Mater. Sci. Mater. Med. 2000, 11, 667-673. [CrossRef]

29. Münch, A.; Please, C.P.; Wagner, B. Spin coating of an evaporating polymer solution. Phys. Fluids 2011, 23, 102101. [CrossRef]

30. Dorozhkin, S.V. Calcium orthophosphate coatings, films and layers. Prog. Biomater. 2012, 1, 1-40. [CrossRef]

31. Wang, M.; Tang, T. Surface treatment strategies to combat implant-related infection from the beginning. J. Orthop. Transl. 2019, 17, 42-54. [CrossRef]

32. Eguia, A.; Arakistain, A.; De-la-Pinta, I.; López-Vicente, J.; Sevillano, E.; Quindós, G.; Eraso, E. Candida albicans biofilms on different materials for manufacturing implant abutments and prostheses. Med. Oral Patol. Oral Cir. Bucal 2020, 25, e13-e20. [CrossRef]

33. Predoi, D.; Iconaru, S.L.; Predoi, M.V.; Stan, G.E.; Buton, N. Synthesis, characterization, and antimicrobial activity of magnesiumdoped hydroxyapatite suspensions. Nanomaterials 2019, 9, 1295. [CrossRef]

34. Ciobanu, C.S.; Iconaru, S.L.; Massuyeau, F.; Constantin, L.V.; Costescu, A.; Predoi, D. Synthesis, structure, and luminescent properties of europium-doped hydroxyapatite nanocrystalline powders. J. Nanomater. 2012, 2012, 942801. [CrossRef]

35. Predoi, D.; Iconaru, S.L.; Predoi, M.V.; Motelica-Heino, M.; Guegan, R.; Buton, N. Evaluation of antibacterial activity of zinc-doped hydroxyapatite colloids and dispersion stability using ultrasounds. Nanomaterials 2019, 9, 515. [CrossRef] [PubMed]

36. Predoi, D.; Iconaru, S.L.; Predoi, M.V.; Motelica-Heino, M. Removal and oxidation of As(III) from water using iron oxide coated CTAB as adsorbent. Polymers 2020, 12, 1687. [CrossRef] [PubMed]

37. Predoi, D.; Iconaru, S.L.; Ciobanu, S.C.; Predoi, S.-A.; Buton, N.; Megier, C.; Beuran, M. Development of iron-doped hydroxyapatite coatings. Coatings 2021, 11, 186. [CrossRef]

38. Predoi, S.-A.; Ciobanu, C.S.; Motelica-Heino, M.; Chifiriuc, M.C.; Badea, M.L.; Iconaru, S.L. Preparation of porous hydroxyapatite using cetyl trimethyl ammonium bromide as surfactant for the removal of lead ions from aquatic solutions. Polymers 2021, 13, 1617. [CrossRef]

39. Gwyddion. Available online: http:/ / gwyddion.net/ (accessed on 20 June 2021).

40. ImageJ. Available online: http:/ /imagej.nih.gov/ij (accessed on 20 June 2021).

41. Iconaru, S.L.; Motelica-Heino, M.; Predoi, D. Study on europium-doped hydroxyapatite nanoparticles by fourier transform infrared spectroscopy and their antimicrobial properties. J. Spectrosc. 2013, 2013, 284285. [CrossRef]

42. Predoi, D.; Groza, A.; Iconaru, S.L.; Predoi, G.; Barbuceanu, F.; Guegan, R.; Motelica-Heino, M.S.; Cimpeanu, C. Properties of basil and lavender essential oils adsorbed on the surface of hydroxyapatite. Materials 2018, 11, 652. [CrossRef]

43. Iconaru, S.L.; Prodan, A.M.; Turculet, C.S.; Beuran, M.; Ghita, R.V.; Costescu, A.; Groza, A.; Chifiriuc, M.C.; Chapon, P.; Gaiaschi, S.; et al. Enamel based composite layers deposited on titanium substrate with antifungal activity. J. Spectrosc. 2016, 2016. [CrossRef]

44. Iconaru, S.L.; Groza, A.; Stan, G.E.; Predoi, D.; Gaiaschi, S.; Trusca, R.; Chifiriuc, C.M.; Marutescu, L.; Tite, T.; Stanciu, G.A.; et al. Preparations of silver/montmorillonite biocomposite multilayers and their antifungal activity. Coatings 2019, 9, 817. [CrossRef]

45. Ciobanu, C.S.; Groza, A.; Iconaru, S.L.; Popa, C.L.; Chapon, P.; Chifiriuc, M.C.; Hristu, R.; Stanciu, G.A.; Negrila, C.C.; Ghita, R.V.; et al. Antimicrobial activity evaluation on silver doped hydroxyapatite/polydimethylsiloxane composite layer. BioMed Res. Int. 2015, 2015, 926513. [CrossRef]

46. ASTM E2149-13a. Standard Test Method for Determining the Antimicrobial Activity of Antimicrobial Agents under Dynamic Contact Conditions; ASTM International: West Conshohocken, PA, USA, 2013.

47. Fuchs, A.V.; Ritz, S.; Pütz, S.; Mailänder, V.; Landfester, K.; Ziener, U. Bioinspired phosphorylcholine containing polymer films with silver nanoparticles combining antifouling and antibacterial properties. Biomater. Sci. 2013, 1, 470-477. [CrossRef]

48. Predoi, D.; Iconaru, S.L.; Predoi, M.V.; Buton, N.; Motelica-Heino, M. Zinc doped hydroxyapatite thin films prepared by sol-gel spin coating procedure. Coatings 2019, 9, 156. [CrossRef]

49. Dukhin, A.S.; Goetz, P.J. Ultrasound for Characterizing Colloids; Elsevier: Amsterdam, The Netherlands, 2002. 
50. Shimizu, K.; Habazaki, H.; Skeldon, P.; Thompson, G.E. Radiofrequency GDOES: A powerful technique for depth profiling analysis of thin films. Surf. Interface Anal. 2003, 35, 564-574. [CrossRef]

51. Reich, S.; Mazur, S.; Avakian, P.; Wilson, F.C. Sintering of silver interlayers in polyimide films. J. Appl. Phys. 1987, 62, 287-292. [CrossRef]

52. Zheng, H.; Berry, D.; Ngo, K.D.; Lu, G.Q. Chip-bonding on copper by pressureless sintering of nanosilver paste under controlled atmosphere. IEEE Trans. Compon. Packag. Manuf. Technol. 2014, 4, 377-384. [CrossRef]

53. Shimizu, K.; Payling, R.; Habazaki, H.; Skeldon, P.; Thompson, G.E. Rf-GDOES depth profiling analysis of a monolayer of thiourea adsorbed on copper. J. Anal. At. Spectrom. 2004, 19, 692-695. [CrossRef]

54. Hultquist, G.; Seo, M.; Leitner, T.; Leygraf, C.; Sato, N. The dissolution behavior of iron, chromium, molybdenum and copper from pure metals and from ferritic stainless-steels. Corros. Sci. 1987, 27, 937-946. [CrossRef]

55. Turculet, C.S.; Prodan, A.M.; Negoi, I.; Teleanu, G.; Popa, M.; Andronescu, E.; Beuran, M.; Stanciu, G.A.; Hristu, R.; Badea, M.L.; et al. Preliminary evaluation of the antifungal activity of samarium doped hydroxyapatite thin films. Rom. Biotechnol. Lett. 2018, 23, 13927-13932. [CrossRef]

56. Jiang, W.U.; Zhang, G.; Jie, L.I.U.; Hongbing, G.A.O.; Chunxiang, S.O.N.G.; Haoran, D.U.; Zhang, L.; Zhongping, G.O.N.G.; Yuguang, L.Ü. Synthesis, characteristics, and antibacterial activity of a rare-earth samarium/silver/titanium dioxide inorganic nanomaterials. J. Rare Earths 2014, 32, 727-732. [CrossRef]

57. Ain, Q.; Pandey, S.K.; Pandey, O.P.; Sengupta, S.K. Synthesis, spectroscopic, thermal and antimicrobial studies of neodymium(III) and samarium(III) complexes derived from tetradentate ligands containing N and S donor atoms. Spectrochim. Acta A Mol. Biomol. Spectrosc. 2015, 140, 27-34. [CrossRef] [PubMed]

58. Nandal, P.; Kumar, R.; Khatkar, A.; Khatkar, P.; Taxak, V.B. Synthesis, characterization, enhanced photoluminescence, antimicrobial and antioxidant activities of novel Sm(III) complexes containing 1-(2-hydroxy-4,6-dimethoxyphenyl)ethanone and nitrogen containing ancillary ligands. J. Mater. Sci. Mater. Electron. 2016, 27, 878-885. [CrossRef]

59. Morais, D.S.; Rodrigues, M.A.; Lopes, M.A.; Coelho, M.J.; Maurıcio, A.C.; Gomes, R.; Amorim, I.; Ferraz, M.P.; Santos, J.D.; Botelho, C.M. Biological evaluation of alginate-based hydrogels, with antimicrobial features by Ce(III) incorporation, as vehicles for a bone substitute. J. Mater. Sci. Mater. Med. 2013, 24, 2145-2155. [CrossRef]

60. Barry, J.N.; Cowley, A.; McNally, P.J.; Dowling, D.P. Influence of substrate metal alloy type on the properties of hydroxyapatite coatings deposited using a novel ambient temperature deposition technique. J. Biomed. Mater. Res. A 2014, 102, 871-879. [CrossRef] [PubMed]

61. Ferraris, S.; Yamaguchi, S.; Barbani, N.; Cristallini, C.; Gautier di Confiengo, G.; Barberi, J.; Cazzola, M.; Miola, M.; Vernè, E.; Sprian, S. The mechanical and chemical stability of the interfaces in bioactive materials: The substrate-bioactive surface layer and hydroxyapatite bioactive surface layer interfaces. Mater. Sci. Eng. C 2020, 116, 111238. [CrossRef] [PubMed] 